\title{
MECHANICAL TESTING OF CARBON STEEL IN HIGH PRESSURE HYDROGEN (U)
}

\author{
Andrew J. Duncan \\ Poh-Sang Lam \\ Savannah River National Laboratory \\ Materials Science \& Technology Directorate
}

Publication Date: May 2006

\section{Washington Savannah River Company Savannah River Site Aiken, SC 29808}

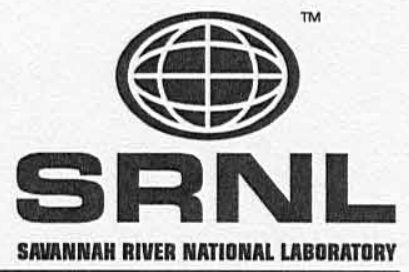

This document was prepared in connection with work done under Contract No. DE-AC09-96SR18500 with the U. S. Department of Energy. Distribution authorized to the Department of Energy only; other requests shall be approved by the cognizant DOE Departmental Element. 


\section{DISCLAIMER}

This report was prepared as an account of work sponsored by an agency of the United States Government. Neither the United States Government nor any agency thereof, nor any of their employees, makes any warranty, express or implied, or assumes any legal liability or responsibility for the accuracy, completeness, or usefulness of any information, apparatus, product, or process disclosed, or represents that its use would not infringe privately owned rights. Reference herein to any specific commercial product, process, or service by trade name, trademark, manufacturer, or otherwise does not necessarily constitute or imply its endorsement, recommendation, or favoring by the United States Government or any agency thereof. The views and opinions of authors expressed herein do not necessarily state or reflect those of the United States Government or any agency thereof. 
DOCUMENT: $\quad$ WSRC-TR-2006-00180, Rev. 0

TITLE: Mechanical Testing of Carbon Steel in High Pressure Hydrogen

\section{APPROVALS}

$\wedge$

A.J. Duncan, Author

Date:

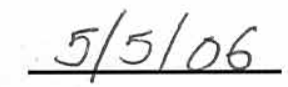

SRNL-MATERIALS SCIENCE \& TECHNOLOGY

Materials Applications \& Process Technology Group

Date: $5 / 5 / 06$

P. S. Lam, Author

SRNL-MATERIALS SCIENCE \& TECHNOLOGY

Materials Applications \& Process Technology Group

T. M. Adams, Technical Review

SRNL-MATERIALS SCIENCE \& TECHNOLOGY

Materials Performance \& Corrosion Technology Group

R. L. Sindelar, Manager

Date: $5-5-06$

SRNL-MATERIALS SCIENCE \& TECHNOLOGY

Matariale $\Delta$ nnlicatione $\&$ Pronece Technology Group

Date: $5 / 5 / 06$

N.Cl Iyer, Director

Date: $\underline{5-5-06}$ 


\section{Table of Contents}

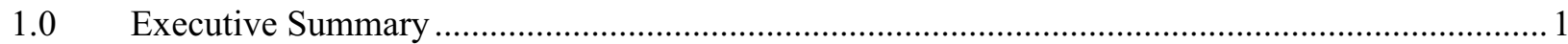

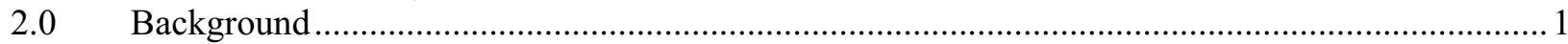

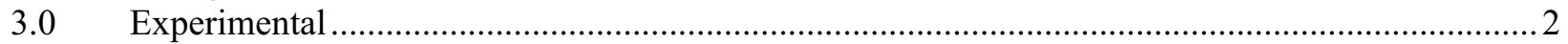

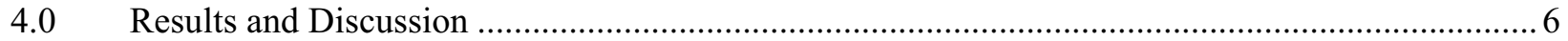

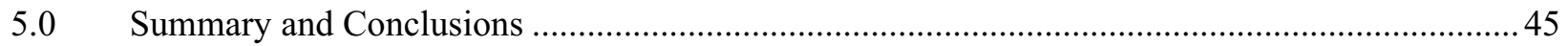

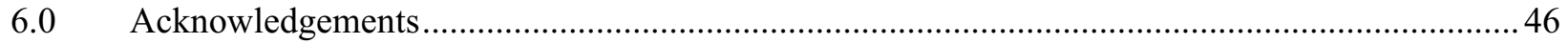

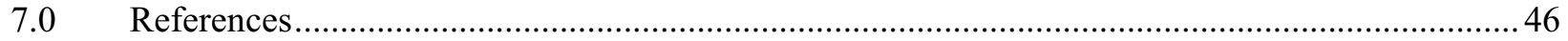

\section{List of Figures}

Figure 1: Photograph of Alloy A 106 Grade B Pipe Section after Welding ............................................ 3

Figure 2: Schematic of Pipe Section illustrating the Orientation of Tensile Specimens ............................ 3

Figure 3: Schematic and Dimensions of Dog bone Tensile Specimen ................................................... 4

Figure 4: Hydrogen Test Load Frame Set Up and Configuration........................................................ 4

Figure 5: Low Magnification Scanning Electron Micrographs of the Fracture Surface from HAZ

Specimens Tested in Air (a) and 1500 psig Hydrogen (b) ....................................................... 7

Figure 6 Higher Magnification Scanning Electron Micrographs of the Fracture Surface from HAZ

Specimens Tested in Air (a) and 1500 psig Hydrogen (b) ..................................................... 8

Figure 7: Engineering Stress vs. Strain for Sample \# 106B001A1 (Base Metal in Air)........................... 9

Figure 8: Engineering Stress vs. Strain for Sample \# 106B001A3 (Base Metal in Air)........................... 10

Figure 9: Engineering Stress vs. Strain for Sample \# 106B001A5 (Base Metal in Air).......................... 11

Figure 10: Engineering Stress vs. Strain Sample \# 106B001A7 (Base Metal in Air) .............................. 12

Figure 11: Engineering Stress vs. Strain for Sample \# 106B001A8 (Base Metal in Air)........................ 13

Figure 12: Engineering Stress vs. Strain for Sample \# 106B001A9 (Base Metal in Air).......................... 14

Figure 13: Engineering Stress vs. Strain for Sample \# 106B100H1 (Base Metal in 1500 psig $\mathrm{H}_{2}$ ) .......... 15

Figure 14: Engineering Stress vs. Strain for Sample \# 106B100H2 (Base Metal in $1500 \mathrm{psig} \mathrm{H}_{2}$ ) .......... 16

Figure 15: Engineering Stress vs. Strain for Sample \# 106B100H3 (Base Metal in 1500 psig $\mathrm{H}_{2}$ ) ........... 17

Figure 16: Engineering Stress vs. Strain for Sample \# 106B100H4 (Base Metal in 1500 psig $\mathrm{H}_{2}$ ) ........... 18

Figure 17: Engineering Stress vs. Strain for Sample \# 106B100H5 (Base Metal in 1500 psig $\mathrm{H}_{2}$ ) ........... 19

Figure 18: Engineering Stress vs. Strain for Sample \# 106B100H6 (Base Metal in 1500 psig $\mathrm{H}_{2}$ ) ...........20

Figure 19: Engineering Stress vs. Strain for Sample \# 106W001A1 (Weld Metal in Air)........................21

Figure 20: Engineering Stress vs. Strain for Sample \# 106W001A2 (Weld Metal in Air)........................22

Figure 21: Engineering Stress vs. Strain for Sample \# 106W001A4 (Weld Metal in Air)........................23

Figure 22: Engineering Stress vs. Strain for Sample \# 106W001A5 (Weld Metal in Air).........................24

Figure 23: Engineering Stress vs. Strain for Sample \# 106W001A6 (Weld Metal in Air)........................25

Figure 24: Engineering Stress vs. Strain for Sample \# 106W001A7 (Weld Metal in Air)........................26

Figure 25: Engineering Stress vs. Strain for Sample \# 106W100H1 (Weld Metal in 1500 psig $\mathrm{H}_{2}$ ) ......... 27

Figure 26: Engineering Stress vs. Strain for Sample \# 106W100H2 (Weld Metal in 1500 psig $\mathrm{H}_{2}$ ) ......... 28

Figure 27: Engineering Stress vs. Strain for Sample \# 106W100H3 (Weld Metal in 1500 psig $\mathrm{H}_{2}$ ) .........29

Figure 28: Engineering Stress vs. Strain for Sample \# 106W100H4 (Weld Metal in 1500 psig $\mathrm{H}_{2}$ ) ......... 30

Figure 29: Engineering Stress vs. Strain for Sample \# 106W100H5 (Weld Metal in 1500 psig $\mathrm{H}_{2}$ ) ......... 31

Figure 30: Engineering Stress vs. Strain for Sample \# 106W100H6 (Weld Metal in 1500 psig $\mathrm{H}_{2}$ ) ......... 32

Figure 31: Engineering Stress vs. Strain for Sample \# 106H001A1 (HAZ in Air) ................................... 33

Figure 32: Engineering Stress vs. Strain for Sample \# 106H001A2 (HAZ in Air) ................................... 34

Figure 33: Engineering Stress vs. Strain for Sample \# 106H001A3 (HAZ in Air) .................................. 35

Figure 34: Engineering Stress vs. Strain for Sample \# 106H001A4 (HAZ in Air) .................................... 36 
Figure 35: Engineering Stress vs. Strain for Sample \# 106H001A5 (HAZ in Air) ................................. 37

Figure 36: Engineering Stress vs. Strain for Sample \# 106H001A6 (HAZ in Air) ................................. 38

Figure 37: Engineering Stress vs. Strain for Sample \# 106H100H1 (HAZ in 1500 psig $\mathrm{H}_{2}$ )................... 39

Figure 38: Engineering Stress vs. Strain for Sample \# 106H100H1 (HAZ in $1500 \mathrm{psig}_{2}$ ) ................. 40

Figure 39: Engineering Stress vs. Strain for Sample \# 106H100H1 (HAZ in 1500 psig $\mathrm{H}_{2}$ ).................. 41

Figure 40: Engineering Stress vs. Strain for Sample \# 106H100H1 (HAZ in $1500 \mathrm{psig} \mathrm{H}_{2}$ ).................. 42

Figure 41: Engineering Stress vs. Strain for Sample \# 106H100H1 (HAZ in $1500 \mathrm{psig} \mathrm{H}_{2}$ )..................... 43

Figure 42: Engineering Stress vs. Strain for Sample \# 106H100H1 (HAZ in 1500 psig H$_{2}$ ) .................. 44

\section{List of Tables}

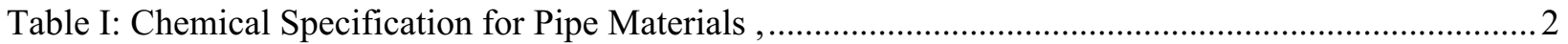

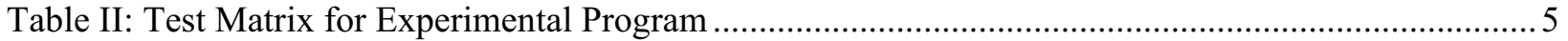

Table III: Mechanical Properties of the Test Matrix................................................................................ 45 


\subsection{EXECUTIVE SUMMARY}

The methods and interim results from a testing program to quantify hydrogen effects on mechanical properties of carbon steel pipeline and pipeline weld materials are provided. The scope is carbon steels commonly used for natural gas pipelines in the United States that are candidates for hydrogen service in the hydrogen economy. The mechanical test results will be applied in future analyses to evaluate service life of the pipelines. The results are also envisioned to be part of the bases for construction codes and structural integrity demonstrations for hydrogen service pipeline and vessels.

Tensile properties of one type of steel (A106 Grade B) in base metal, welded and heat affected zone conditions were tested at room temperature in air and high pressure (1500 psig) hydrogen. A general reduction in the materials ability to plastically deform was noted in this material when specimens were tested in 1500 psig hydrogen. Furthermore, the primary mode of fracture was changed from ductile rupture in air to cleavage with secondary tearing in hydrogen.

The mechanical test program will continue with tests to quantify the fracture behavior in terms of J-R curves for these materials at air and hydrogen pressure conditions.

\subsection{BACKGROUND}

An infrastructure of new and existing pipelines and systems will be required to carry and to deliver hydrogen as an alternative energy source under the hydrogen economy. Carbon and low alloy steels of moderate strength are currently used in hydrogen delivery systems as well as in the existing natural gas systems. It is critical to understand the material response of these standard pipeline materials specified by the American Petroleum Institute (API) when they are subject to pressurized gases of pure hydrogen or its mixture with methane since hydrogen is well known in deteriorating the mechanical properties of steels.

A literature survey for existing mechanical property data on carbon and low alloy steels exposed to hydrogen gas was conducted to support the program led by the Concurrent Technologies Corporation for hydrogen pipeline life management. Data needs were identified certain materials. Among those identified, data for tests in hydrogen at a standard method was needed.

Tensile data for carbon steels in hydrogen atmospheres (100 ATM) was planned to develop a data set for transmission pipelines. Three pipe alloys were considered for the initial study. Alloys API X42, API X70 and ASTM A106 grade B were chosen because of their wide utilization in the pipeline industry. The compositional requirements from each specification are listed in Table I. Alloy A106 grade B was eventually chosen for the initial portion of the study because the particular pipe section available had a large wall thickness, which left ample material for the machining of specimens and could be sectioned with the entire gage section intersecting the base metal, heat affected zone or weld metal. This report documents the interim results from the testing of specimens machined from this welded pipe section. 
Table I: Chemical Specification for Pipe Materials ${ }^{1,2}$

\begin{tabular}{|c|c|c|c|}
\hline & \multicolumn{3}{|c|}{ Composition, \% } \\
\hline & A 106 Grade B & API X42 (welded) & API X70 (welded) \\
\hline Carbon, $\max ^{\mathrm{A}}$ & 0.3 & 0.26 & 0.26 \\
\hline Manganese & $0.29-1.06$ & $1.3(\max )$ & $1.65(\max )$ \\
\hline Phosphorus, max & 0.035 & 0.03 & 0.03 \\
\hline Sulfur, max & 0.035 & 0.03 & 0.03 \\
\hline Silicon, min & 0.1 & & \\
\hline Chrome, $\max ^{\mathrm{B}}$ & 0.4 & & \\
\hline Copper, $\max ^{\mathrm{B}}$ & 0.4 & & \\
\hline Molybdenum, $\max ^{\mathrm{B}}$ & 0.15 & & \\
\hline Nickel, $\max ^{B}$ & 0.4 & & \\
\hline Vanadium, $\max ^{\mathrm{B}}$ & 0.08 & & \\
\hline Titanium, max & & 0.06 & 0.06 \\
\hline
\end{tabular}

${ }^{\mathrm{A}}$ For each reduction of $0.01 \%$ below the specified carbon maximum, an increase of $0.06 \%$ manganese above the specified maximum will be permitted up to a maximum of $1.35 \%$.

${ }^{\mathrm{B}}$ These five elements combined shall not exceed $1 \%$.

\subsection{EXPERIMENTAL}

A section of 4" schedule XXH pipe (4.5 inches OD X 0.674 inches wall thickness) was circumferentially welded using welding procedure specification WPS-P1-TA. ${ }^{3}$ The multi-pass SMAW weld was performed with certification and without any post weld heat treatment. The root pass of the weld was performed by gas tungsten arc welding (GTAW) with filler rod ER70S-2 filler rod, while each remaining pass used shielded metal arc welding (SMAW) with E7018 filler rod. Figure 1 shows a picture of the pipe section after welding.

After the weld procedure was complete the pipe was sectioned in the using electro-discharge milling (EDM) and tensile specimens were machined in the L-C orientation (see Figure 2). Specimens were machined in a "dog bone" configuration from the pipe section with the gage section intersecting the base metal, weld metal and HAZ regions of the pipe (see Figure 3). The initial tests were performed at ambient temperatures and atmospheric conditions (see Table II). Also, additional samples were tested in 1500 psig research grade hydrogen gas $(99.999 \%$ pure).

The specimens were tested at room temperature (i.e. $64-78^{\circ} \mathrm{F}$ ) on a screw driven MTS Sintech Renew $1125 \mathrm{load}$ frame with a $1000 \mathrm{lb}$ load cell at a strain rate of $1 \times 10^{-4} \mathrm{in} / \mathrm{in} / \mathrm{sec}$. The load frame is located inside a hydrogen environmental test facility at SRNL which utilizes engineering controls to ensure flammable gas concentrations in the facility are maintained below the lower flammability limit and engineered barriers to protect personnel from an explosion. The data was collected using MTS Testworks $^{\mathrm{TM}}$ v3.1 data acquisition software.

The specimens that were tested in hydrogen were loaded into a high-pressure vessel manufactured by Autoclave Engineering ${ }^{\mathrm{TM}}$ that is equipped with a translational feedthrough. The chamber was constrained in the load frame (to prevent premature loading of the specimen), purged with inert gas several times and pressurized to $1500 \mathrm{psig}$. The soak time in hydrogen gas, at pressure, was 30 minutes. The pressure was controlled remotely using an independent control system utilizing LabView ${ }^{\mathrm{TM}} \mathrm{v} 5.0$ software. A picture of the test set up is shown in Figure 4. 
The tests were performed to failure and the specimens were examined after the test to measure reduction in area, to verify plastic strain to failure and to characterize the fracture surface. Optical microscopy and scanning electron microscopy were utilized to accomplish this analysis. The raw data of load and crosshead deflection were analyzed using a technique to compensate for machine compliance and slippage in the grip section. The procedure for this correction is described in a study by Lam et al. ${ }^{4}$. Engineering stress and strain were calculated and plotted in the results and discussion.

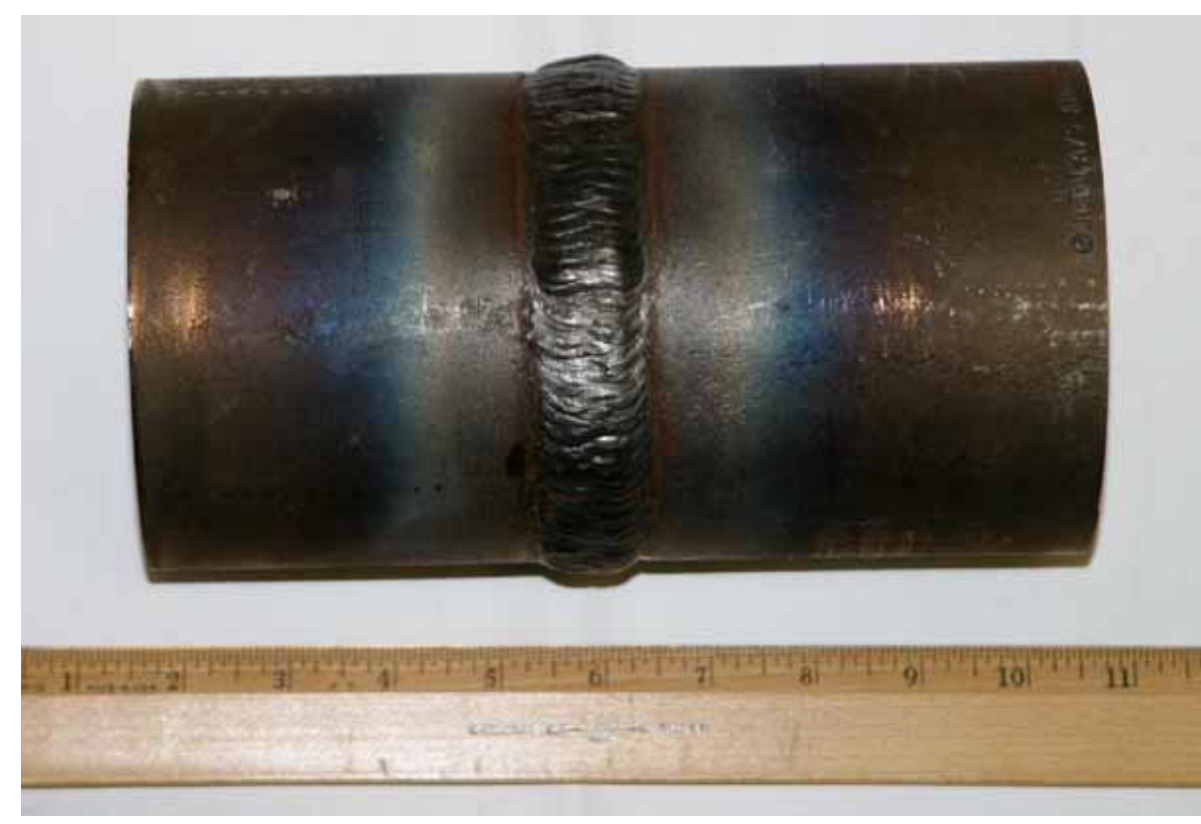

Figure 1: Photograph of Alloy A 106 Grade B Pipe Section after Welding

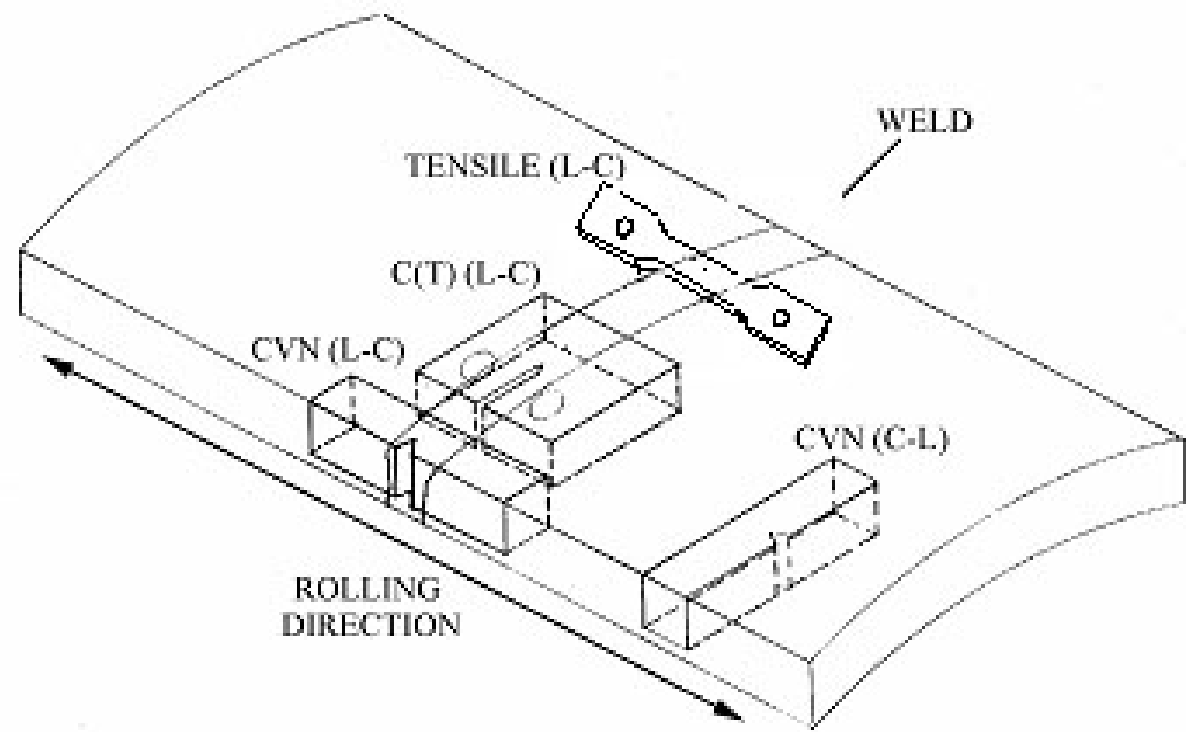

Figure 2: Schematic of Pipe Section illustrating the Orientation of Tensile Specimens 


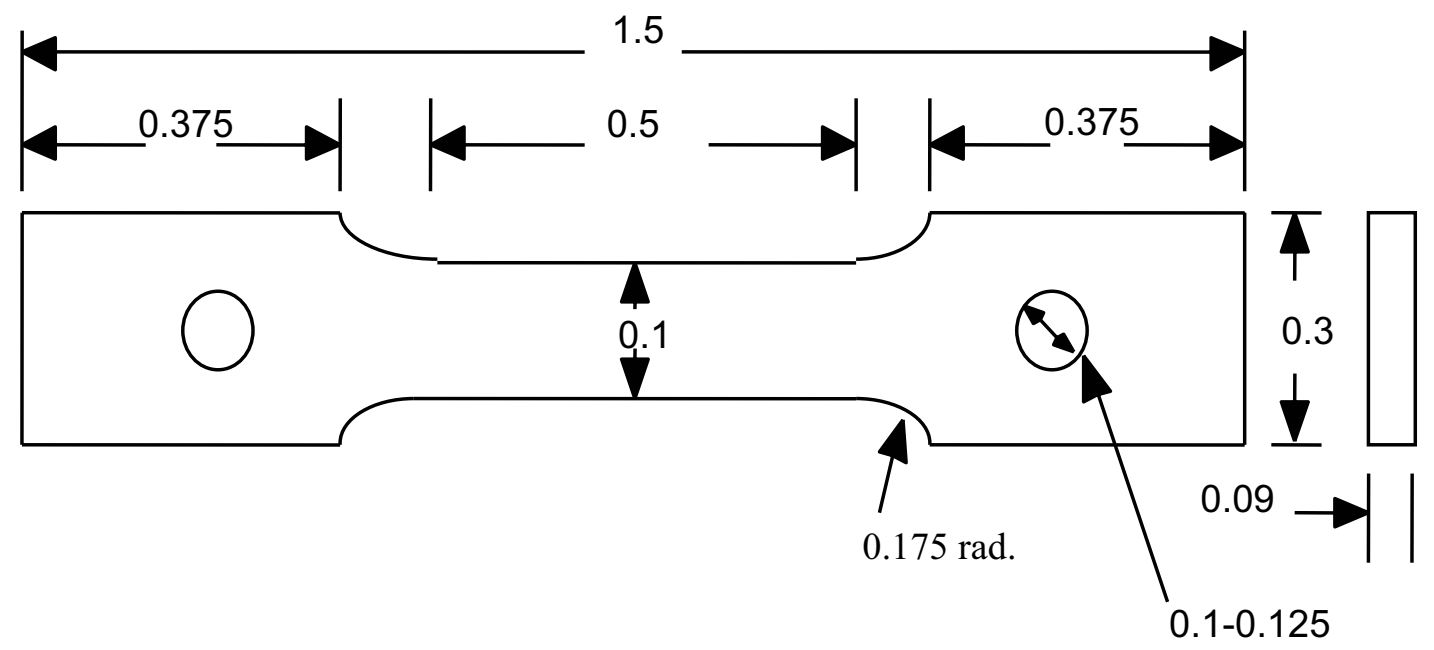

All dimensions in inches

Figure 3: Schematic and Dimensions of Dog bone Tensile Specimen

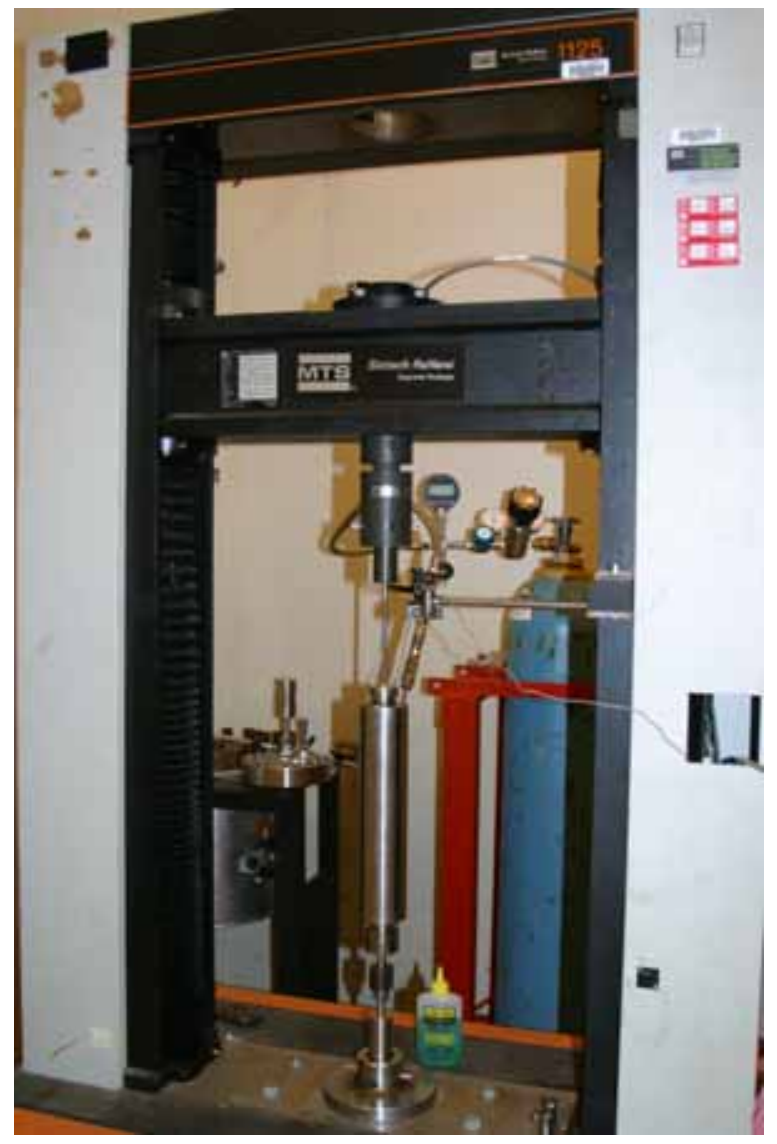

Figure 4: Hydrogen Test Load Frame Set Up and Configuration 
Table II: Test Matrix for Experimental Program

\begin{tabular}{|c|c|c|c|}
\hline 106 Grade B & Sample & 1 ATM (Air) & 100 ATM (H2) \\
\hline \multirow{6}{*}{ Base Metal } & 1 & 106B001A1 & 106B100H1 \\
\hline & 2 & 106B001A3 & 106B100H2 \\
\hline & 3 & 106B001A5 & 106B100H3 \\
\hline & 4 & 106B001A7 & 106B100H4 \\
\hline & 5 & 106B001A8 & 106B100H5 \\
\hline & 6 & 106B001A9 & 106B100H6 \\
\hline \multirow{6}{*}{ Weld Metal } & 1 & 106W001A1 & 106W100H1 \\
\hline & 2 & 106W001A2 & $106 \mathrm{~W} 100 \mathrm{H} 2$ \\
\hline & 3 & 106W001A4 & 106W100H3 \\
\hline & 4 & 106W001A6 & 106W100H4 \\
\hline & 5 & 106W001A7 & 106W100H5 \\
\hline & 6 & 106W001A8 & 106W100H6 \\
\hline \multirow{6}{*}{ HAZ } & 1 & $106 \mathrm{H} 001 \mathrm{~A} 1$ & $106 \mathrm{H} 100 \mathrm{H} 1$ \\
\hline & 2 & $106 \mathrm{H} 001 \mathrm{~A} 2$ & $106 \mathrm{H} 100 \mathrm{H} 2$ \\
\hline & 3 & $106 \mathrm{H} 001 \mathrm{~A} 3$ & $106 \mathrm{H} 100 \mathrm{H} 3$ \\
\hline & 4 & 106H001A4 & $106 \mathrm{H} 100 \mathrm{H} 4$ \\
\hline & 5 & 106H001A5 & $106 \mathrm{H} 100 \mathrm{H} 5$ \\
\hline & 6 & 106H001A6 & $106 \mathrm{H} 100 \mathrm{H} 6$ \\
\hline
\end{tabular}




\subsection{RESULTS AND DISCUSSION}

The changes resulting from exposure of carbon steels to hydrogen environments is well known. As stated in the review of the related open literature ${ }^{5}$,

"...the deformation capacity (ductility), fracture mechanics properties including fracture toughness and fatigue crack propagation characteristics are deteriorated as the hydrogen pressure increases."

The behavior of this "deformation capacity" is illustrated when the fracture surfaces of tensile specimens are examined for specimens tested in air versus hydrogen. For example, Figure 5 ( $a$ and $b$ ) shows the fracture surfaces for the HAZ tensile specimens tested in air and 1500 psig hydrogen at low magnification Figure $6(a$ and $b)$ shows the fracture surfaces for the same HAZ tensile specimens at higher magnification. From these figures, the effects of hydrogen on the deformation capacity can be readily observed. Specifically, the overall "reduction in area" in the necked region is significantly greater in the specimen tested in air (see Figure 5). The morphology of the fracture surface is also changed; Figure 6 shows a reduction in ductile rupture (i.e., void growth and coalescence) in the specimen tested in hydrogen. This behavior is consistent with what has been observed in studies, previously.

Much of the data generated from study in this area has yielded data which is more applicable to academic study of the subject. In order to provide a consensus of properties for design of hydrogen systems, a mechanical properties database should be developed for each material selected for this type of application. This requires the use a statistically valid number of specimens for each testing condition. In the present study, 6 test conditions with 6 specimens per test condition were performed $(36$ specimens in all). The test matrix, shown in Table II, lists the sample names for each specimen in the test program. On occasion, difficulties with the data acquisition system or test equipment required an additional specimen be tested. To eliminate confusion additional specimen numbers were used. Hence, the test matrix shows (see Table II) shows specimen numbers high than 6, in some cases. The engineering stress vs. engineering strain curves are presented in Figures 7-42 for the specimens listed in Table II. The mechanical property data for the test matrix is presented in Table III. From the presentation of the data, it can be observed that no significant changes occur in yield stress or ultimate tensile stress. However, a mild reduction in elongation to failure is observed. Reduction of area is a property that must be measured after the test and is very sensitive to small differences in the deformation behavior of the material. Although the reduction of area data was not available for this report, Figures 5 and 6 indicate that the reduction of area property is expected to be consistent with the elongation to failure exhibited in Table III. 


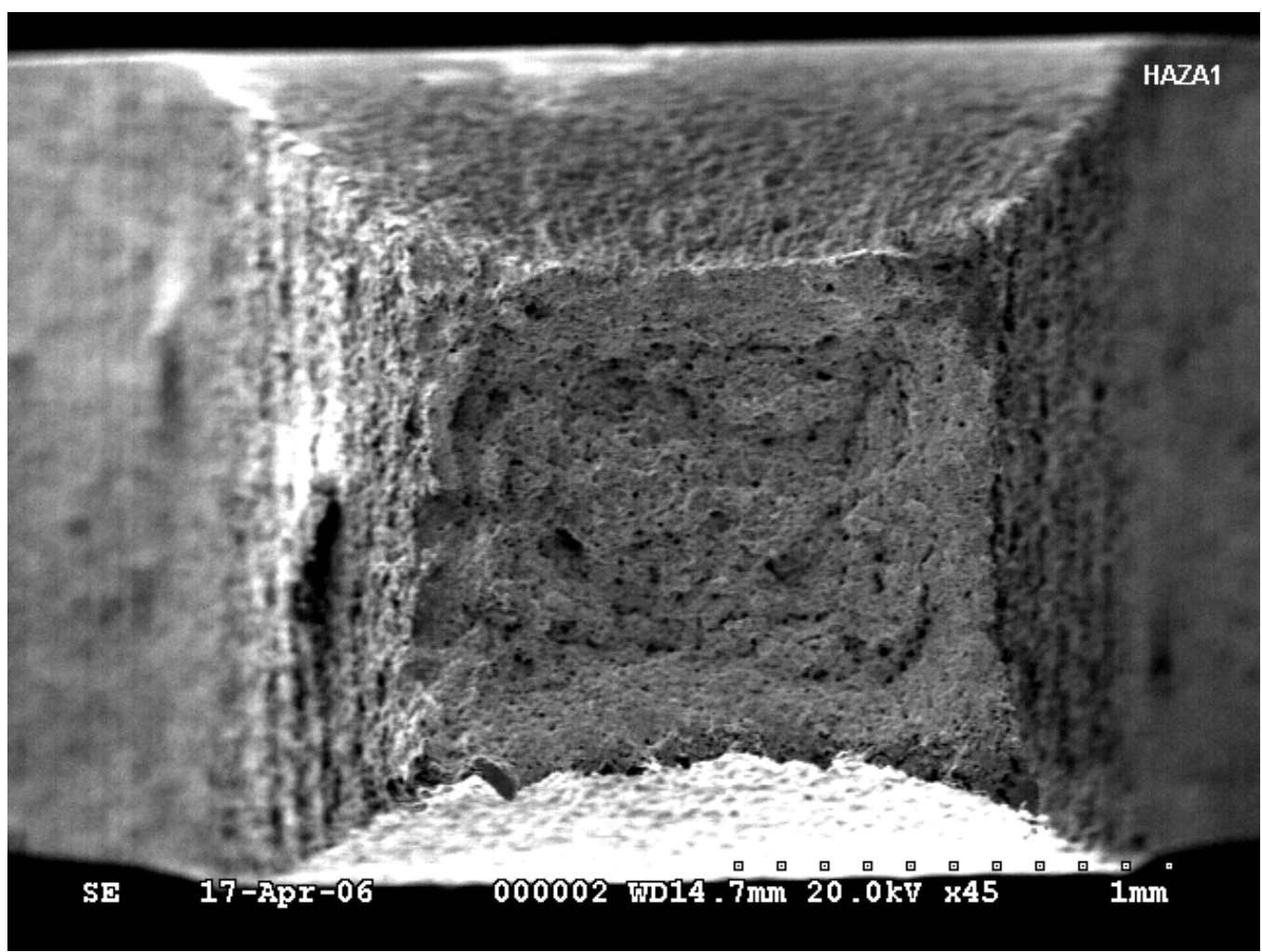

(a)

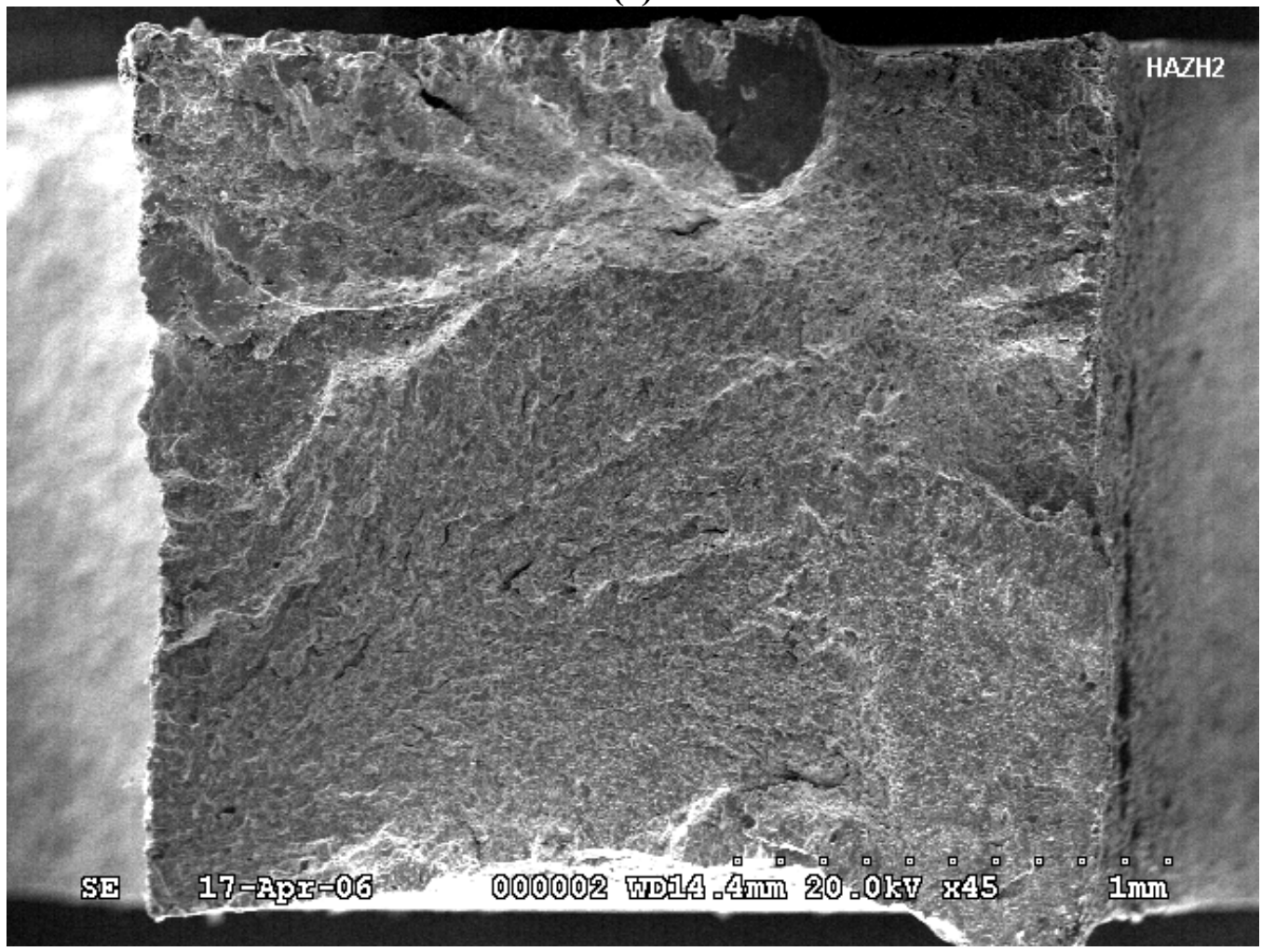

(b)

Figure 5: Low Magnification Scanning Electron Micrographs of the Fracture Surface from HAZ Specimens Tested in Air (a) and 1500 psig Hydrogen (b) 


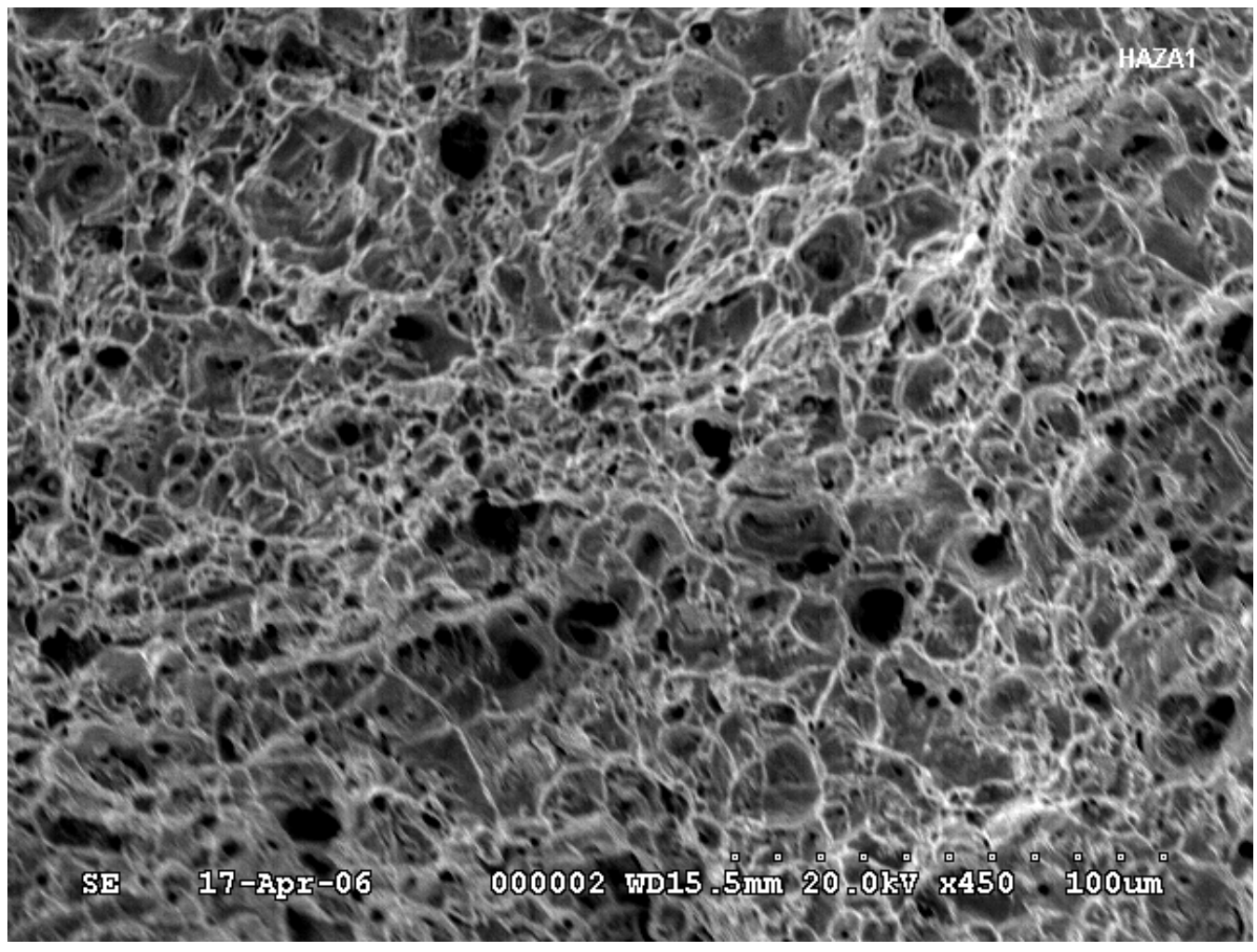

(a)

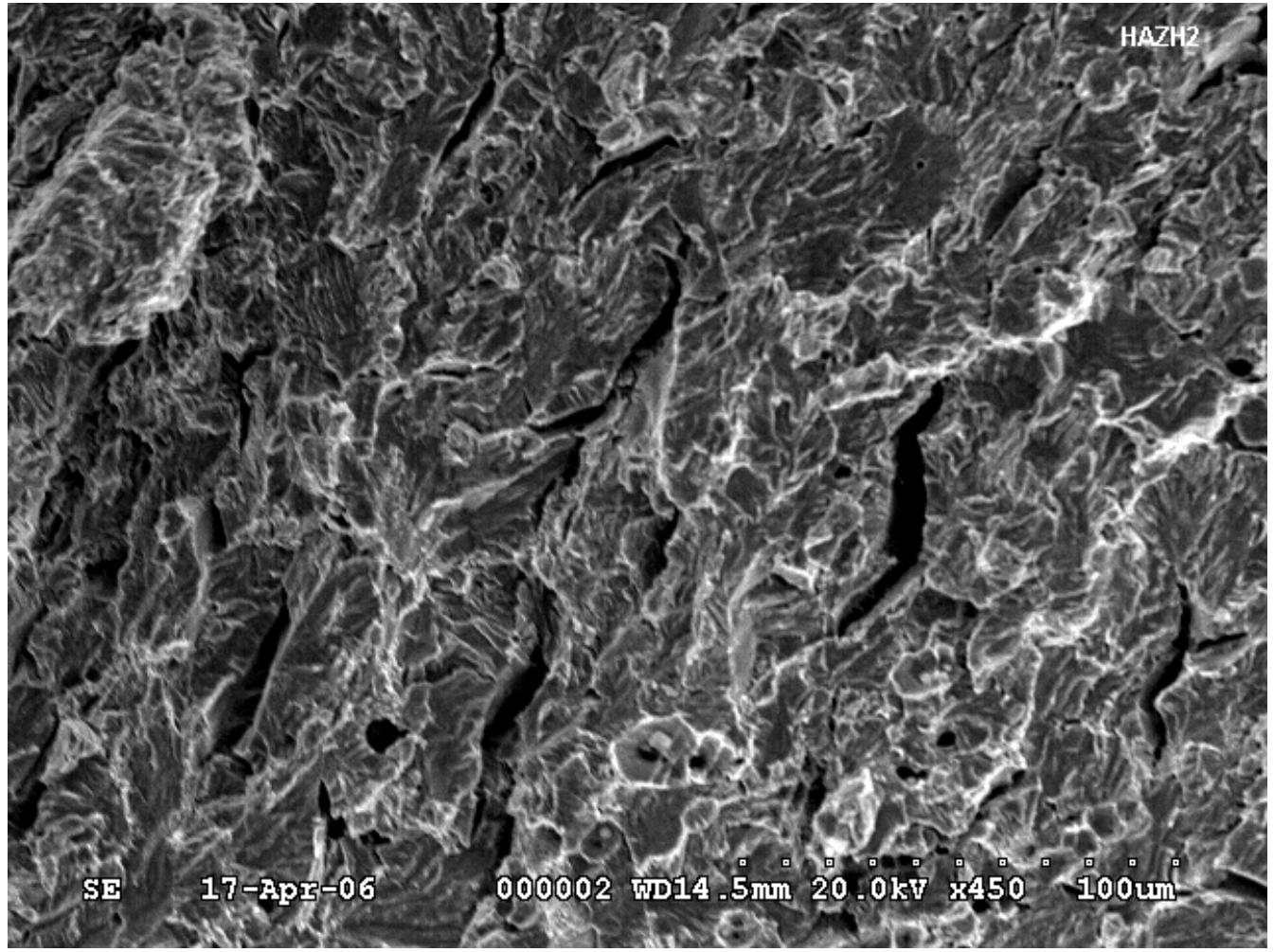

(b)

Figure 6 Higher Magnification Scanning Electron Micrographs of the Fracture Surface from HAZ Specimens Tested in Air (a) and 1500 psig Hydrogen (b) 


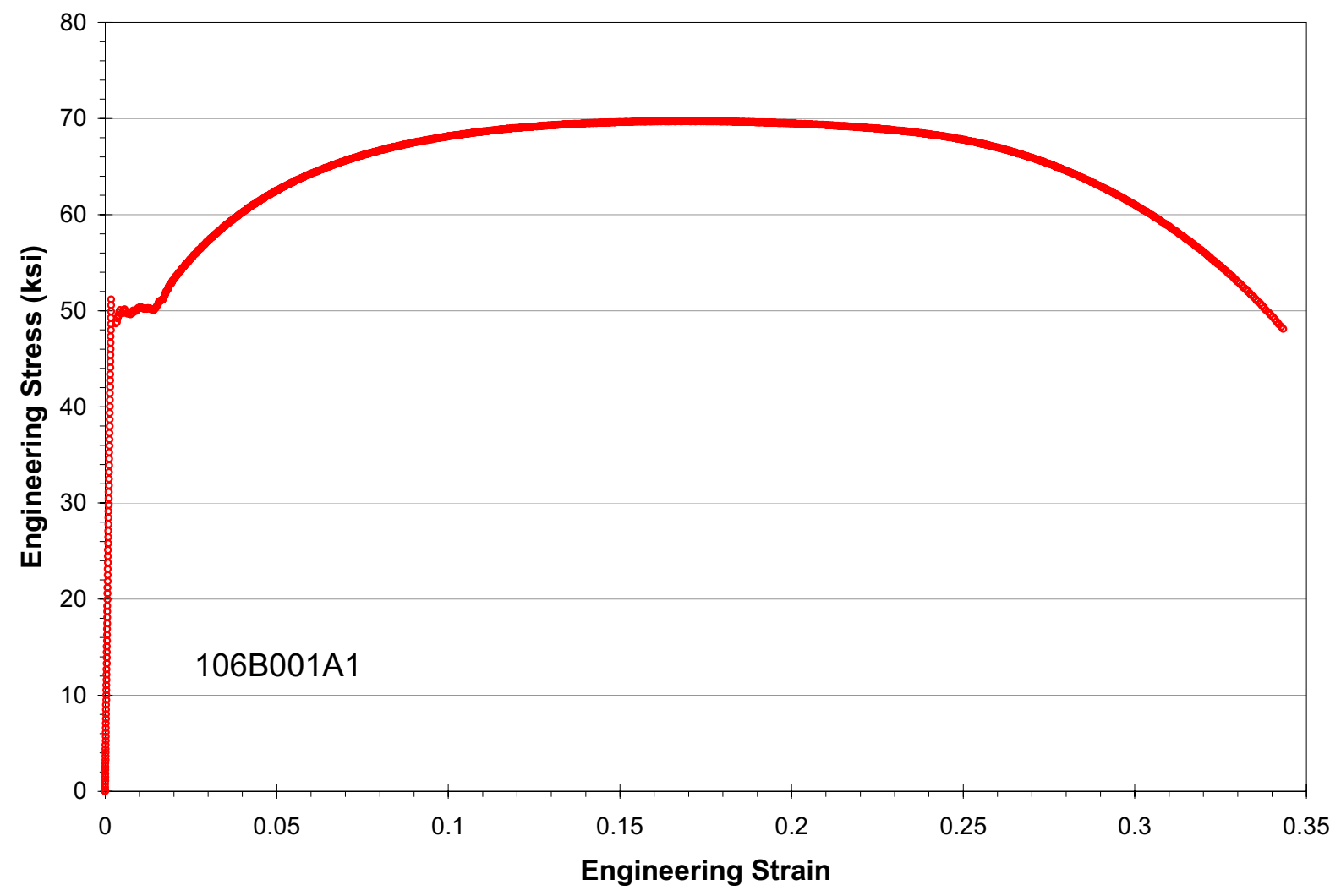

Figure 7: Engineering Stress vs. Strain for Sample \# 106B001A1 (Base Metal in Air) 


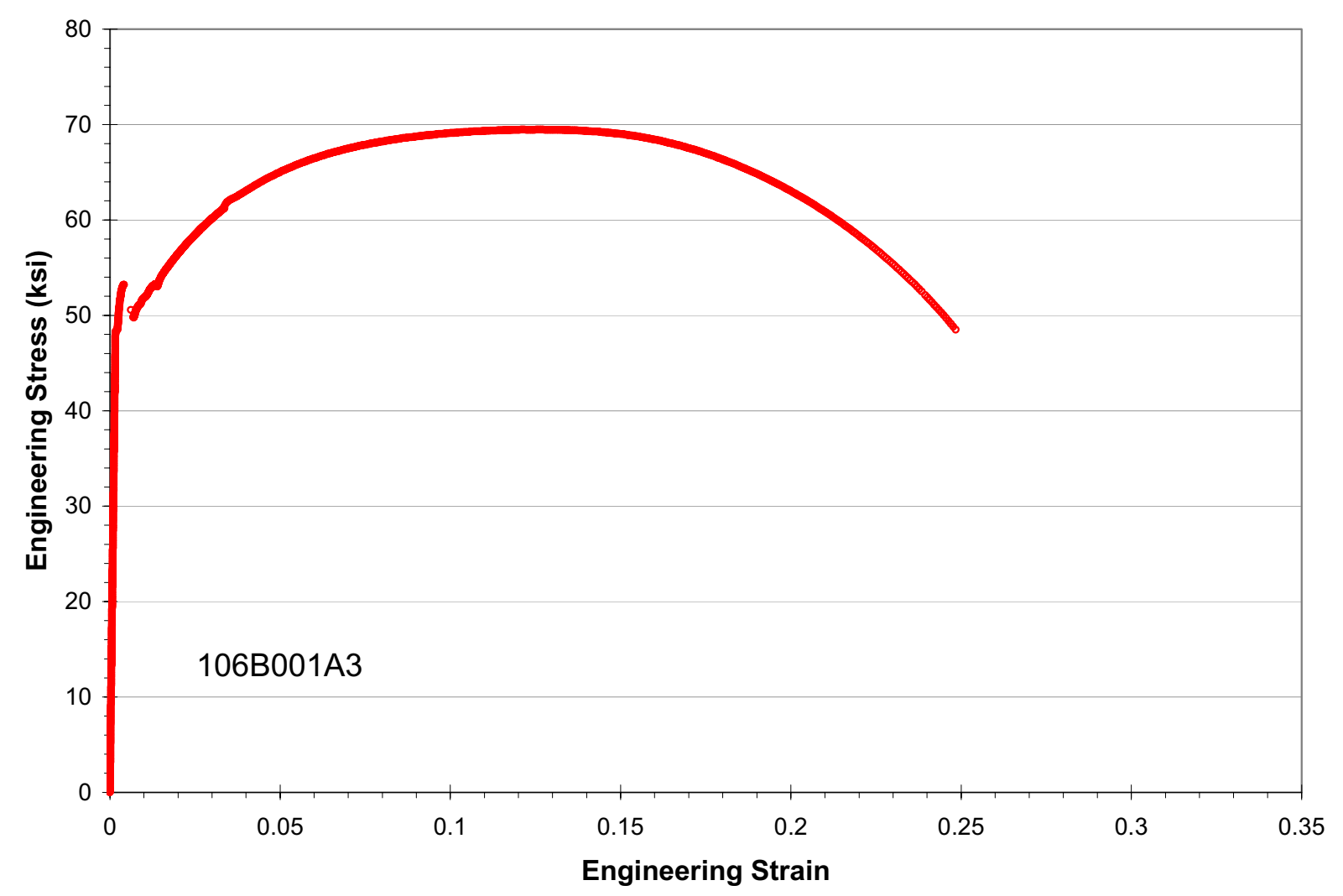

Figure 8: Engineering Stress vs. Strain for Sample \# 106B001A3 (Base Metal in Air) 


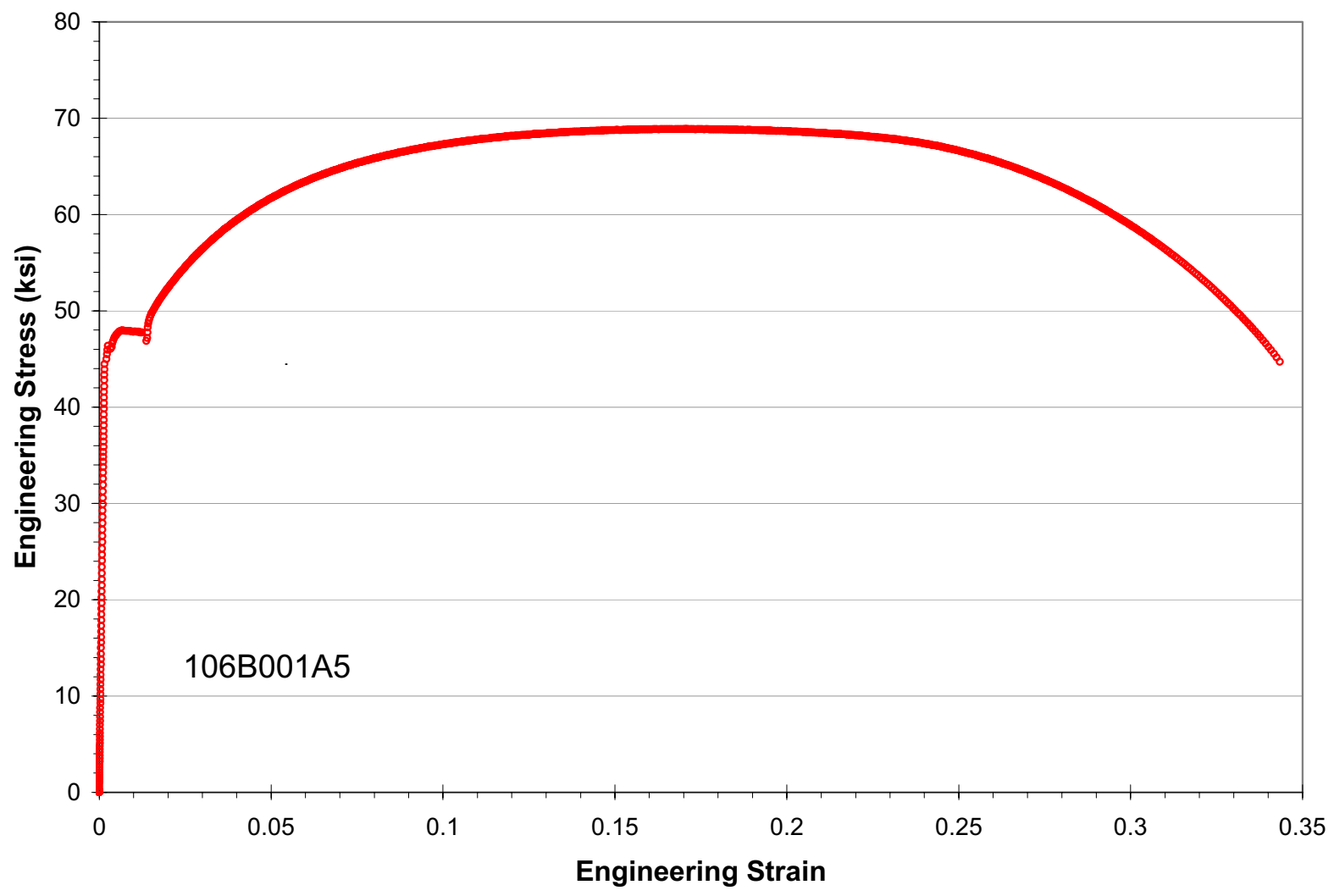

Figure 9: Engineering Stress vs. Strain for Sample \# 106B001A5 (Base Metal in Air) 


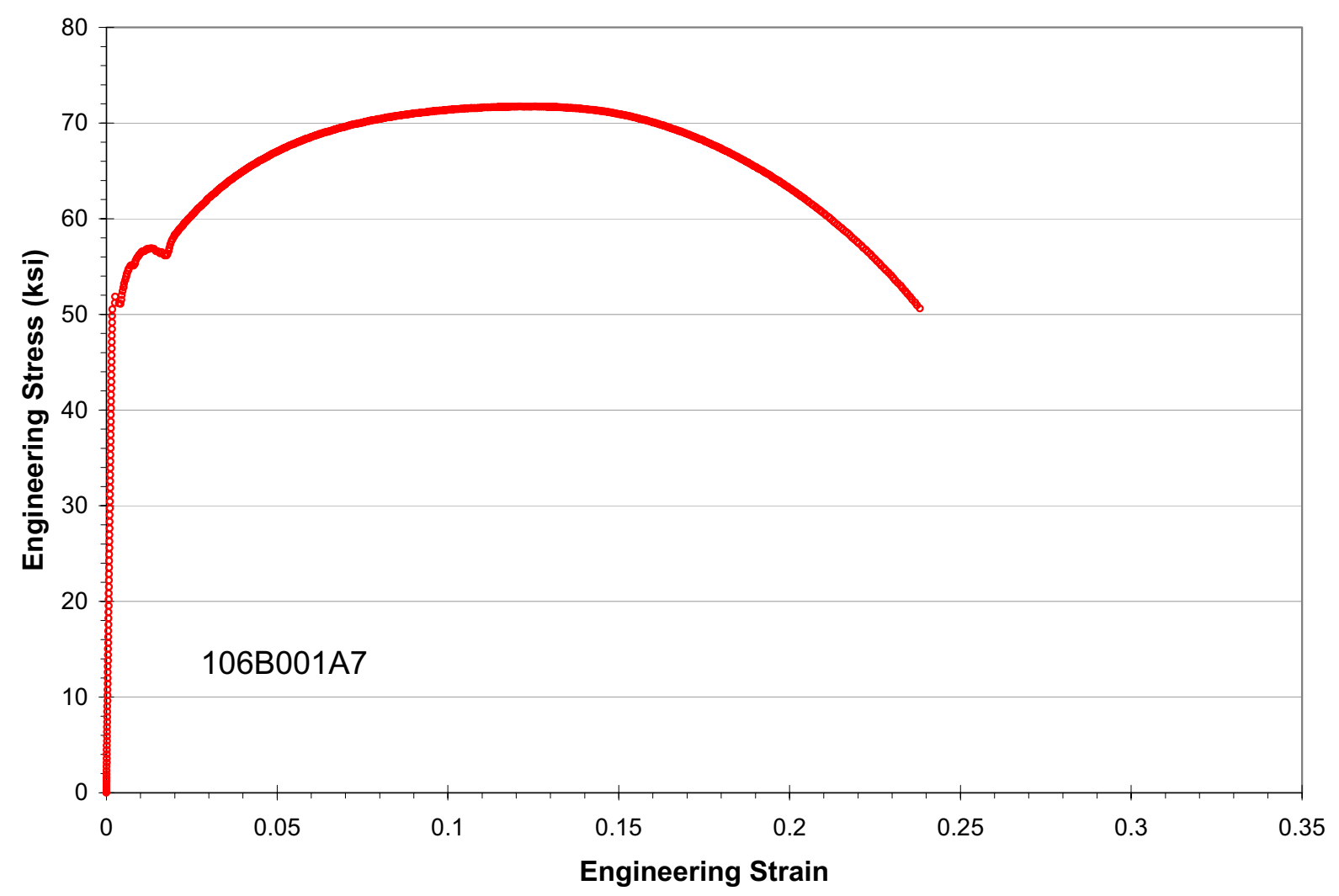

Figure 10: Engineering Stress vs. Strain Sample \# 106B001A7 (Base Metal in Air) 


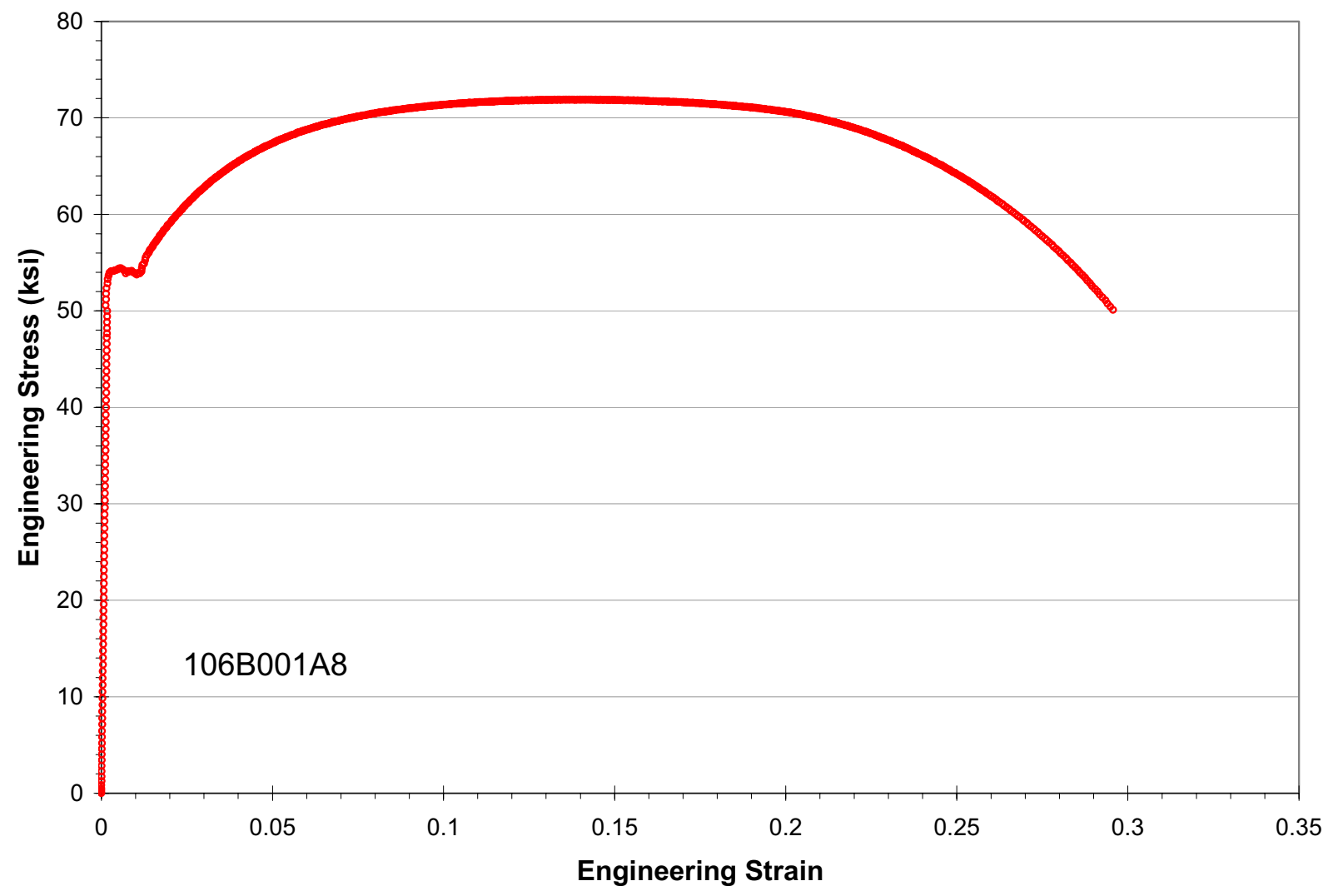

Figure 11: Engineering Stress vs. Strain for Sample \# 106B001A8 (Base Metal in Air) 


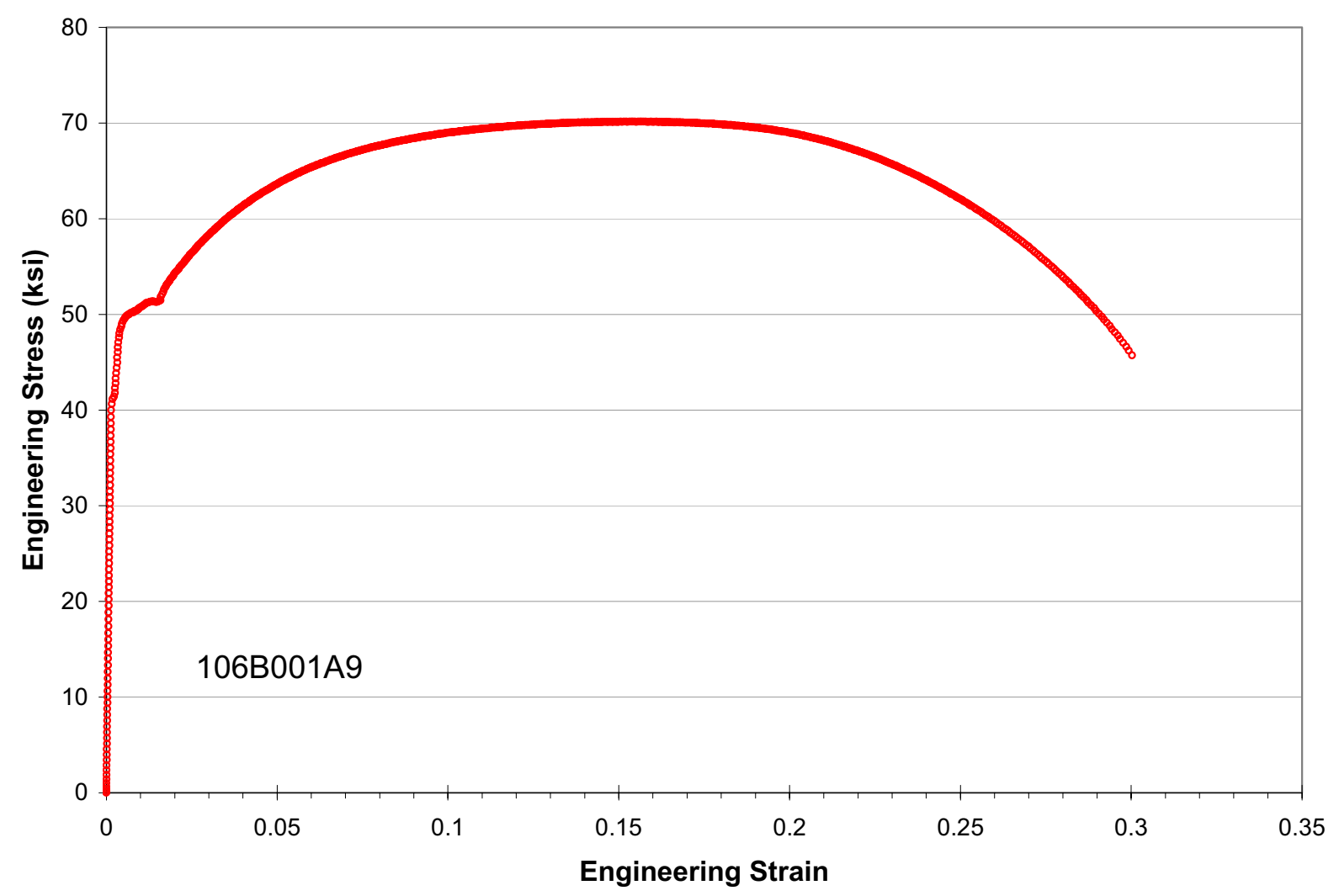

Figure 12: Engineering Stress vs. Strain for Sample \# 106B001A9 (Base Metal in Air) 


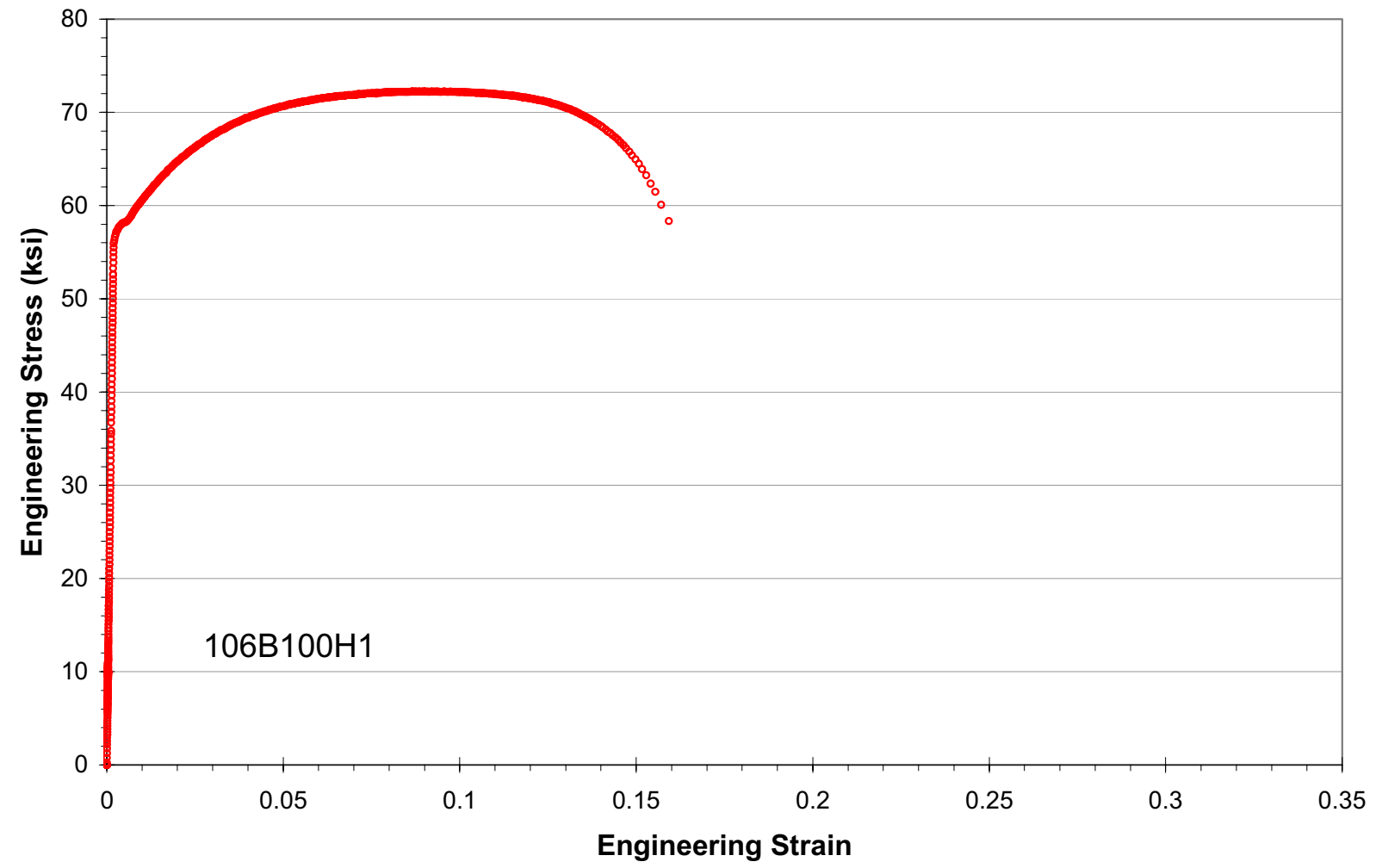

Figure 13: Engineering Stress vs. Strain for Sample \# 106B100H1 (Base Metal in 1500 psig $\mathbf{H}_{2}$ ) 


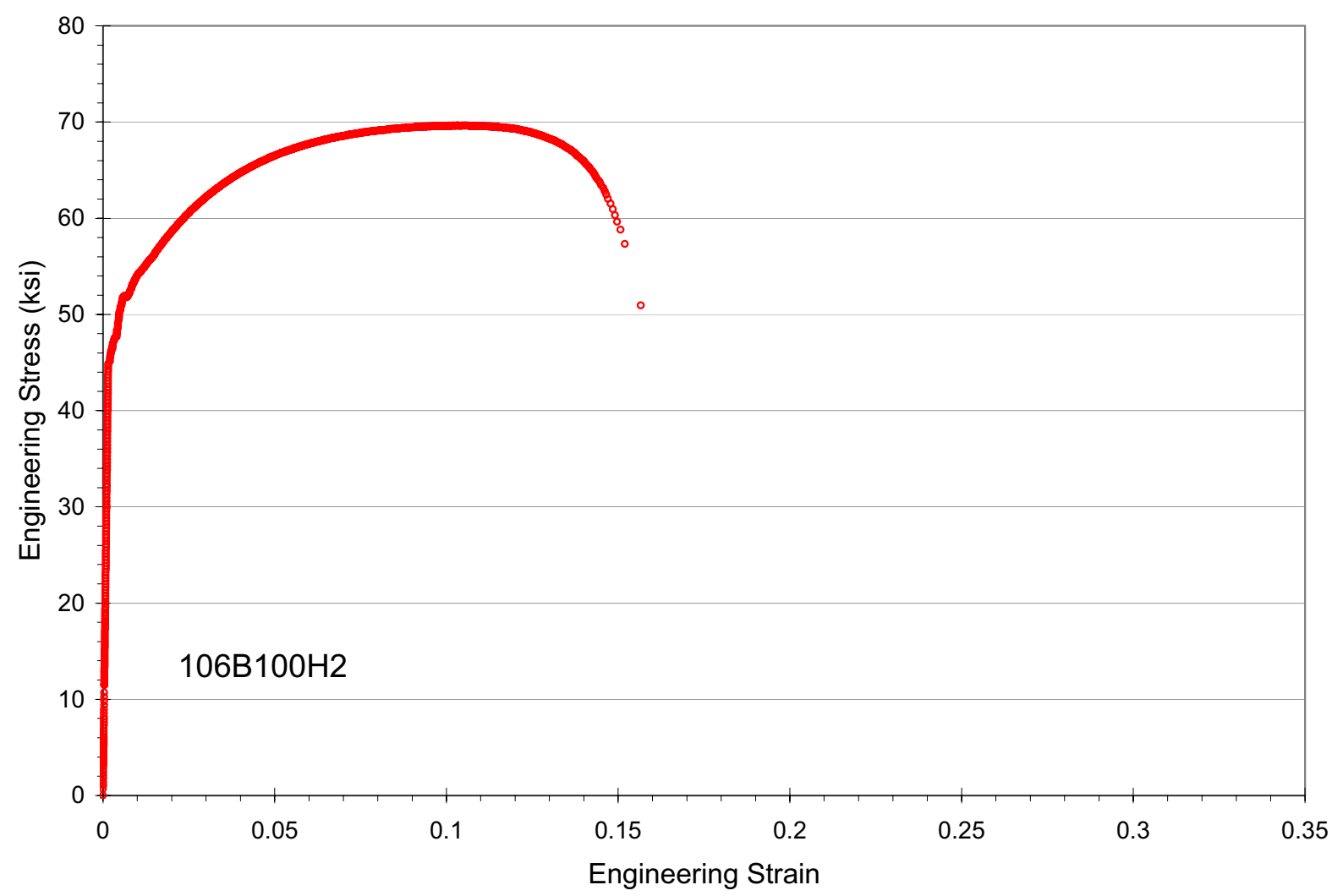

Figure 14: Engineering Stress vs. Strain for Sample \# 106B100H2 (Base Metal in 1500 psig $\mathbf{H}_{2}$ ) 


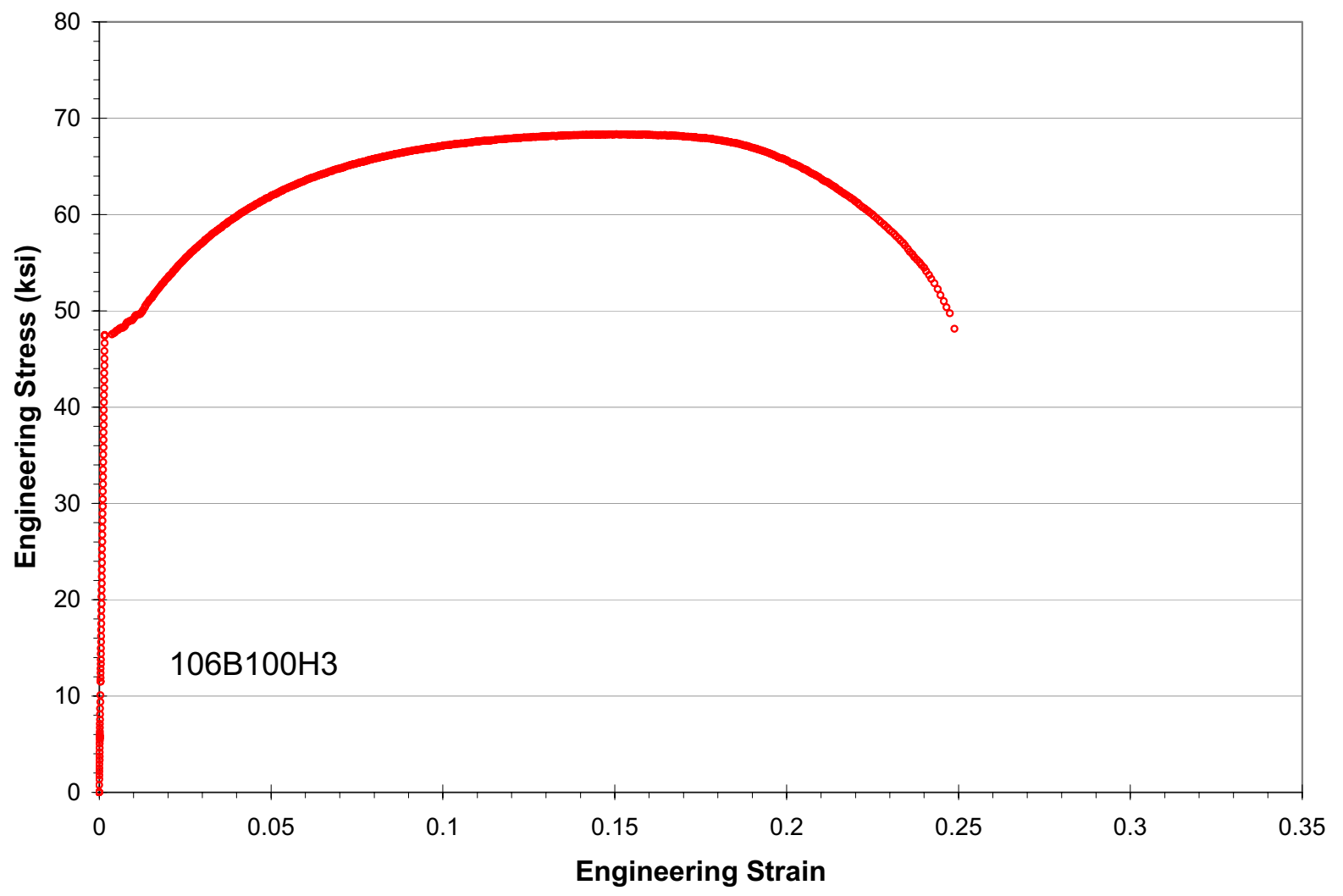

Figure 15: Engineering Stress vs. Strain for Sample \# 106B100H3 (Base Metal in 1500 psig $\mathbf{H}_{2}$ ) 


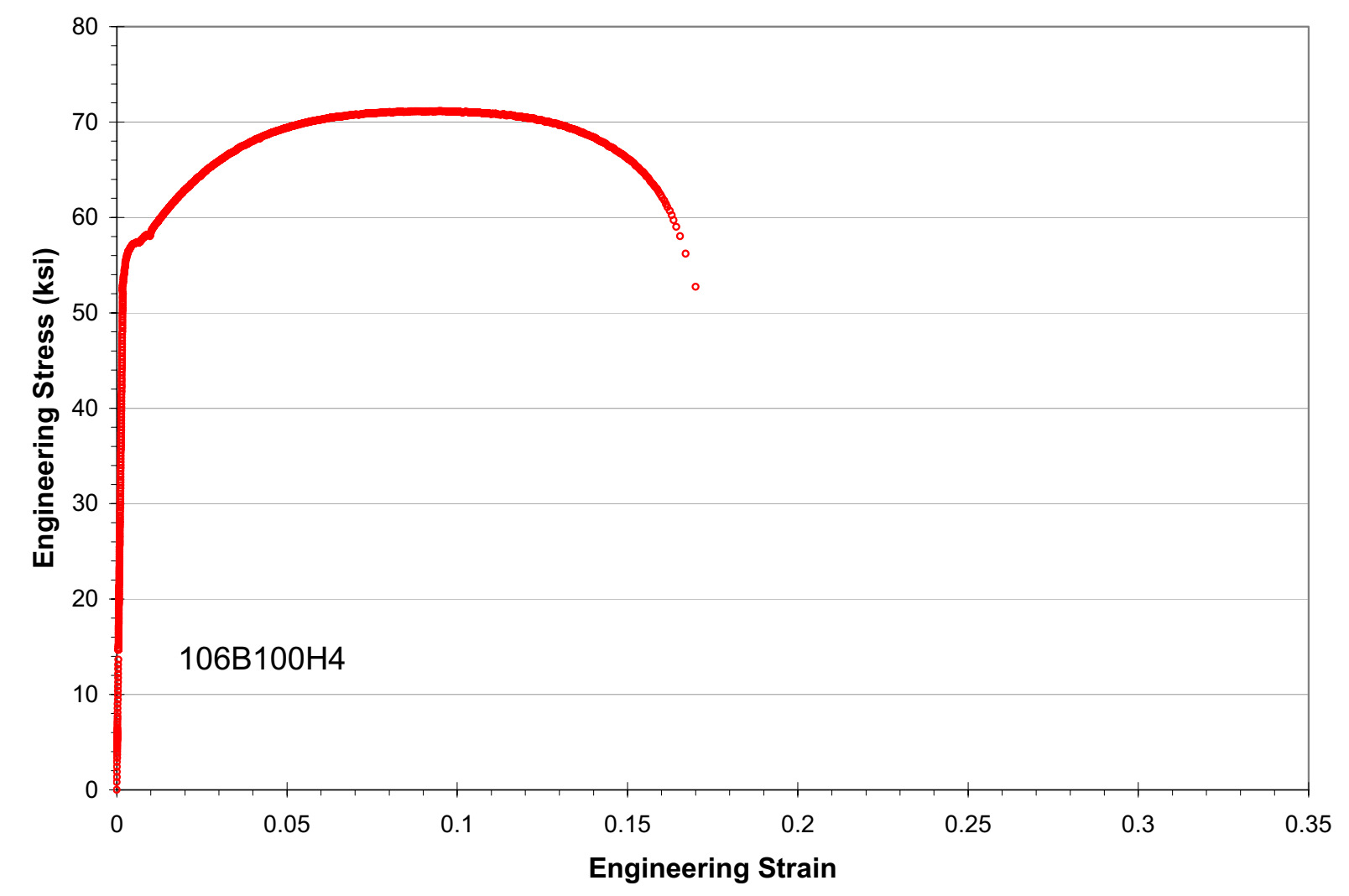

Figure 16: Engineering Stress vs. Strain for Sample \# 106B100H4 (Base Metal in 1500 psig $\mathbf{H}_{2}$ ) 


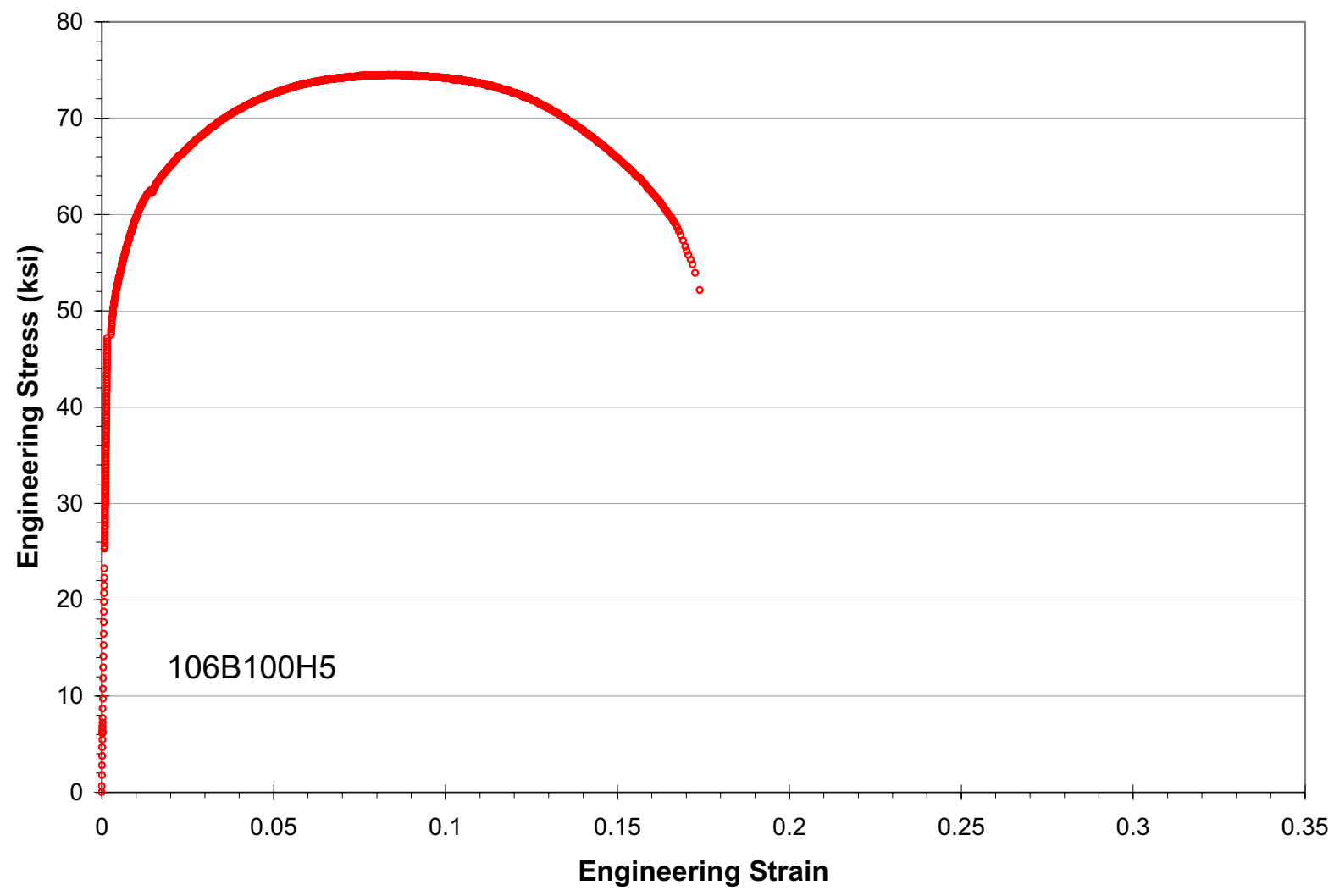

Figure 17: Engineering Stress vs. Strain for Sample \# 106B100H5 (Base Metal in 1500 psig $\mathbf{H}_{2}$ ) 


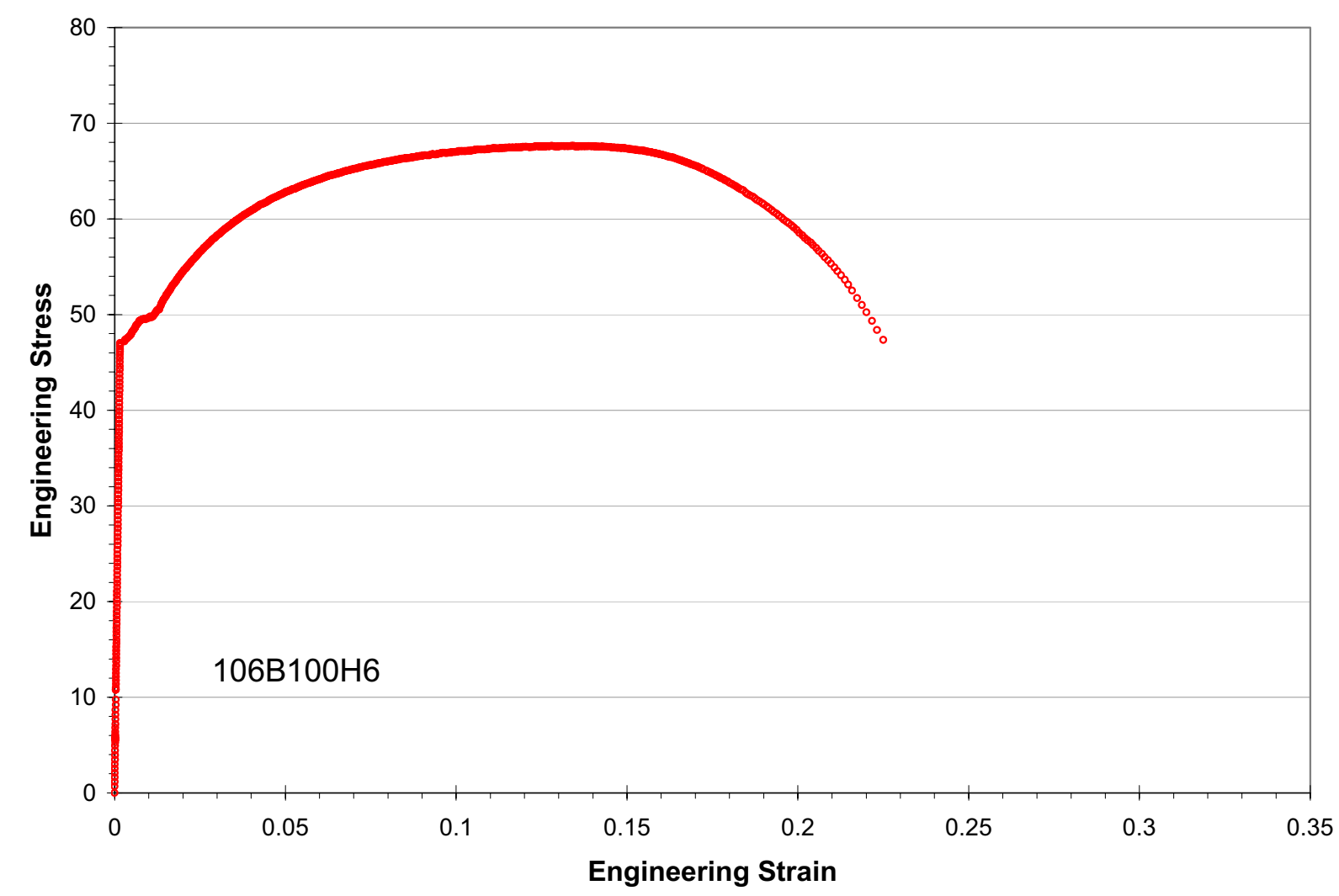

Figure 18: Engineering Stress vs. Strain for Sample \# 106B100H6 (Base Metal in 1500 psig $\mathbf{H}_{2}$ ) 


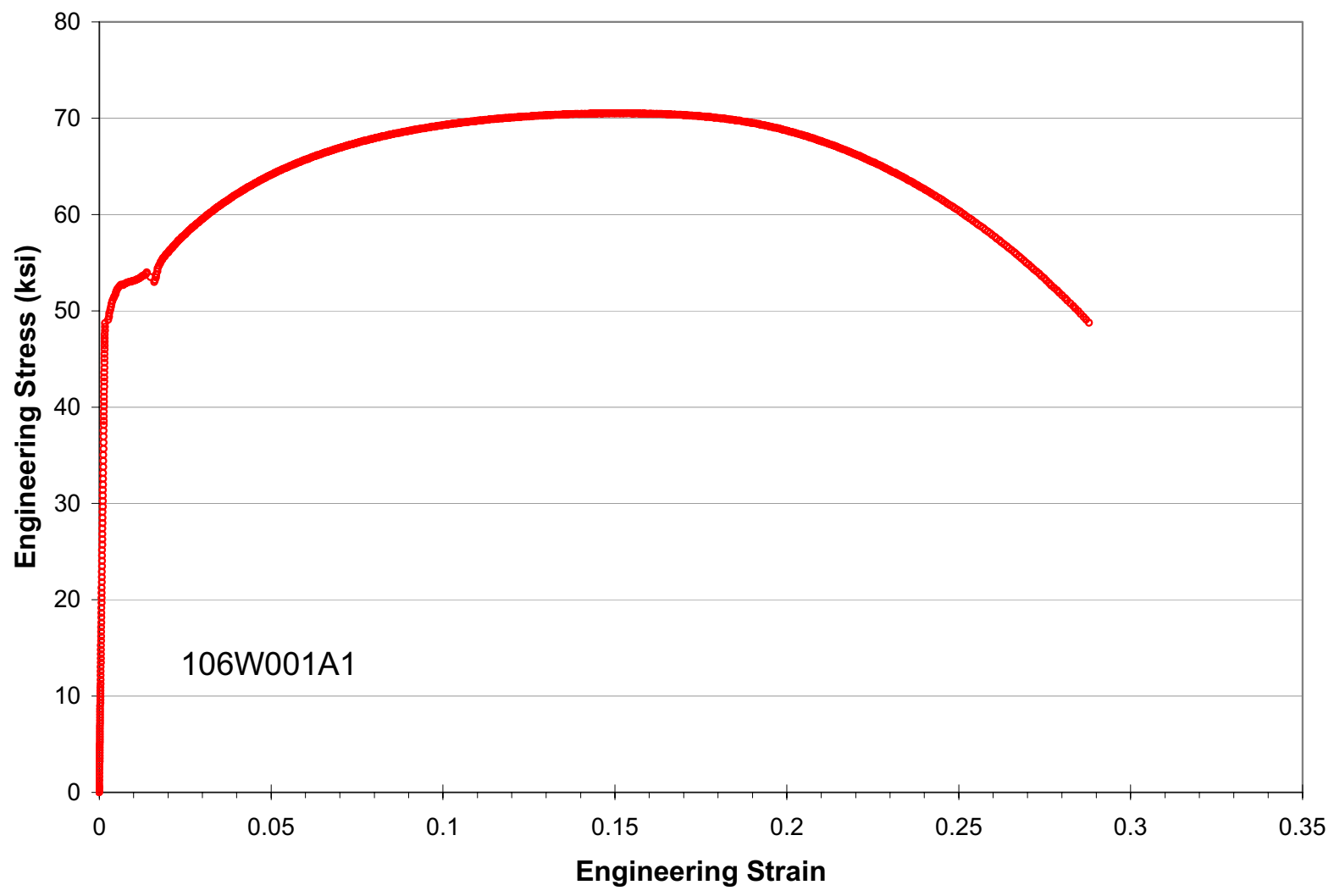

Figure 19: Engineering Stress vs. Strain for Sample \# 106W001A1 (Weld Metal in Air) 


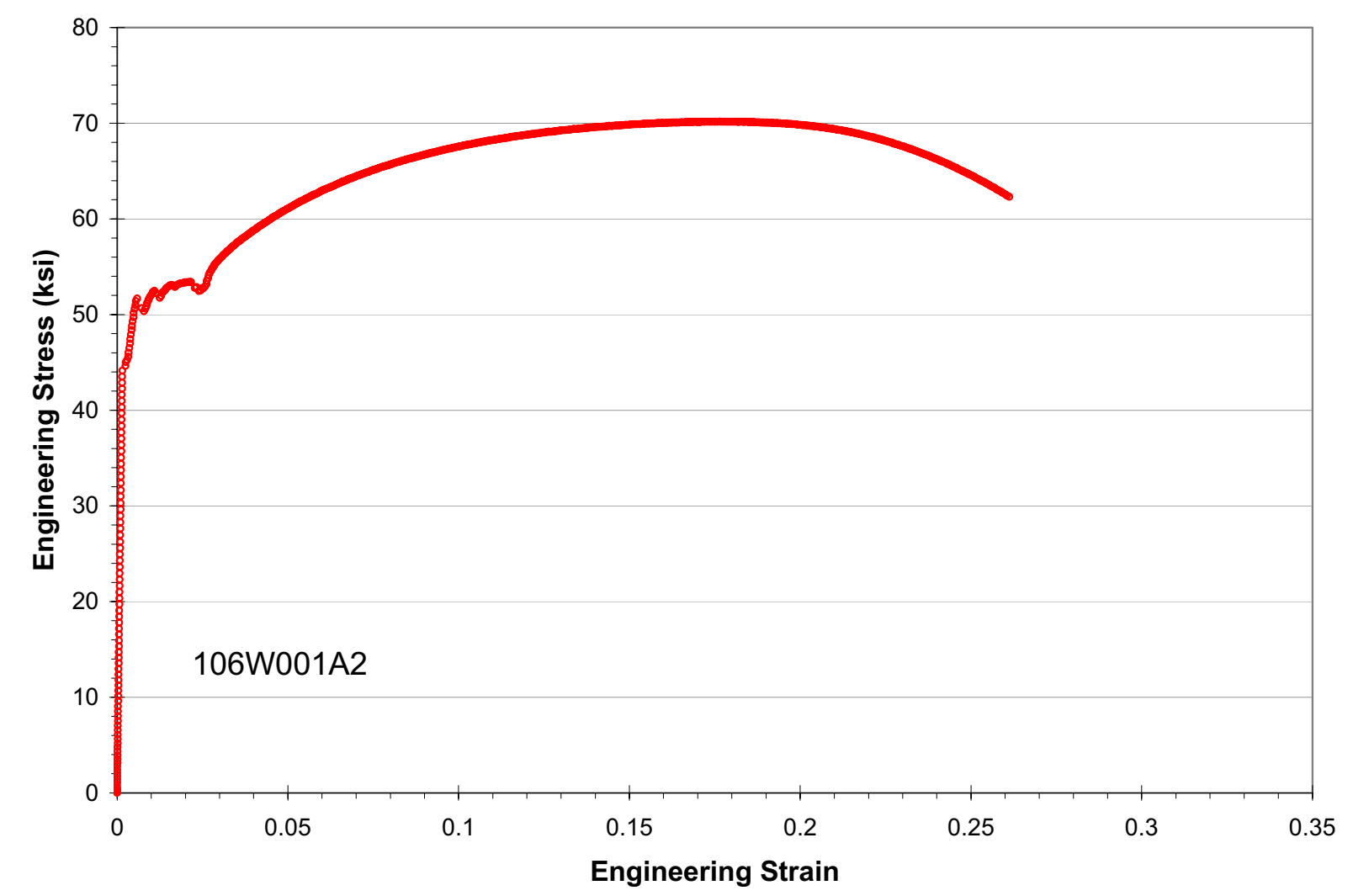

Figure 20: Engineering Stress vs. Strain for Sample \# 106W001A2 (Weld Metal in Air) 


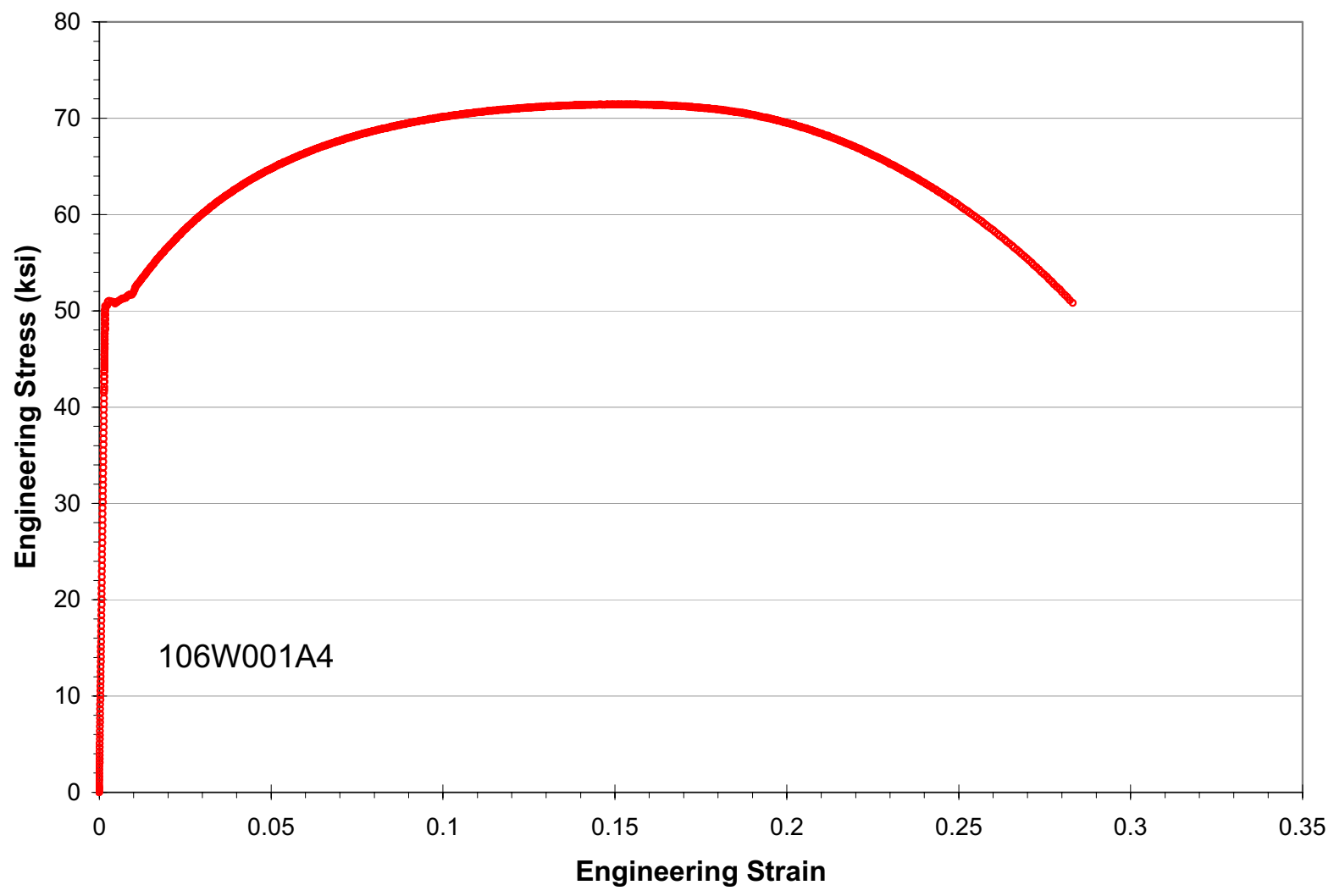

Figure 21: Engineering Stress vs. Strain for Sample \# 106W001A4 (Weld Metal in Air) 


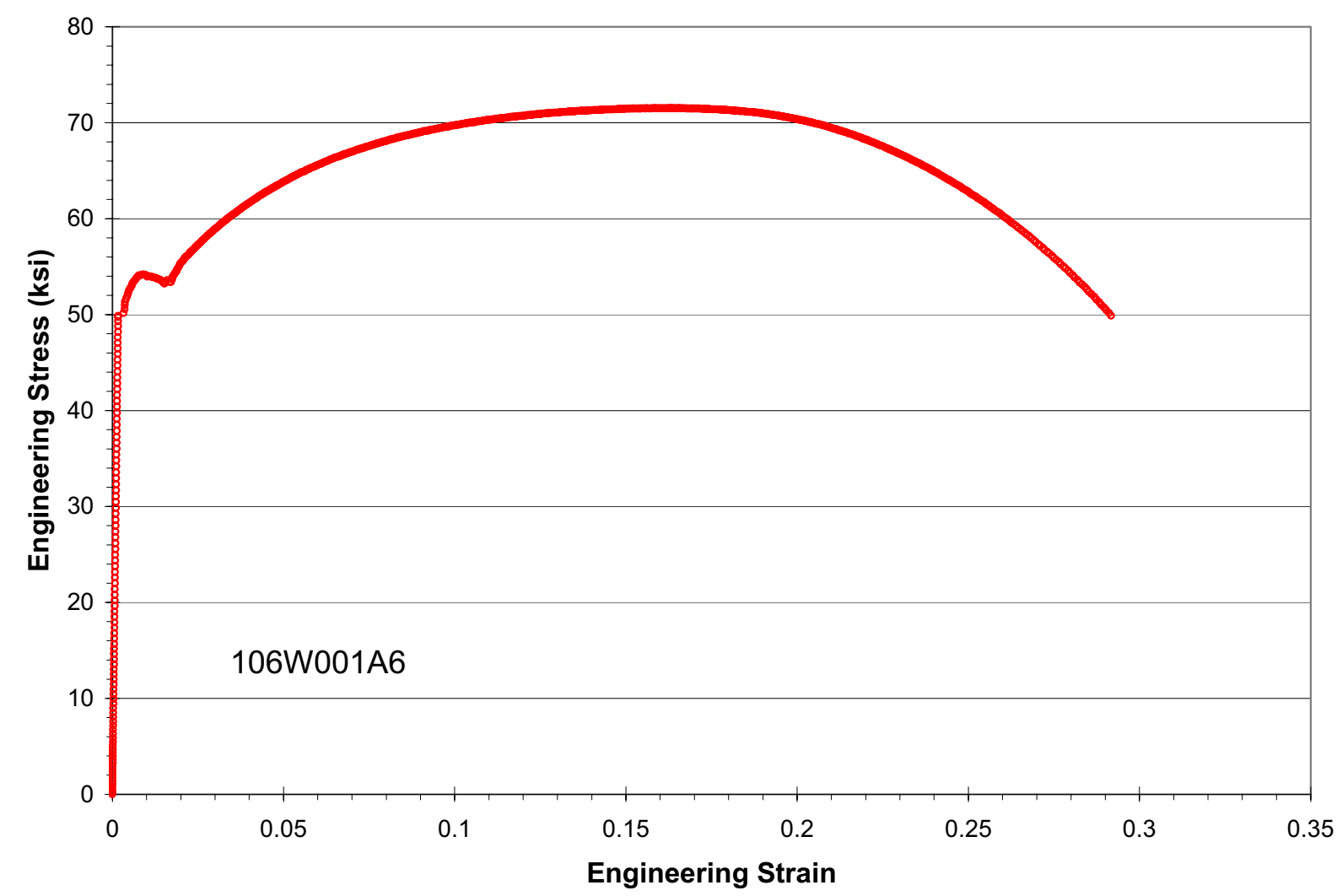

Figure 22: Engineering Stress vs. Strain for Sample \# 106W001A6 (Weld Metal in Air) 


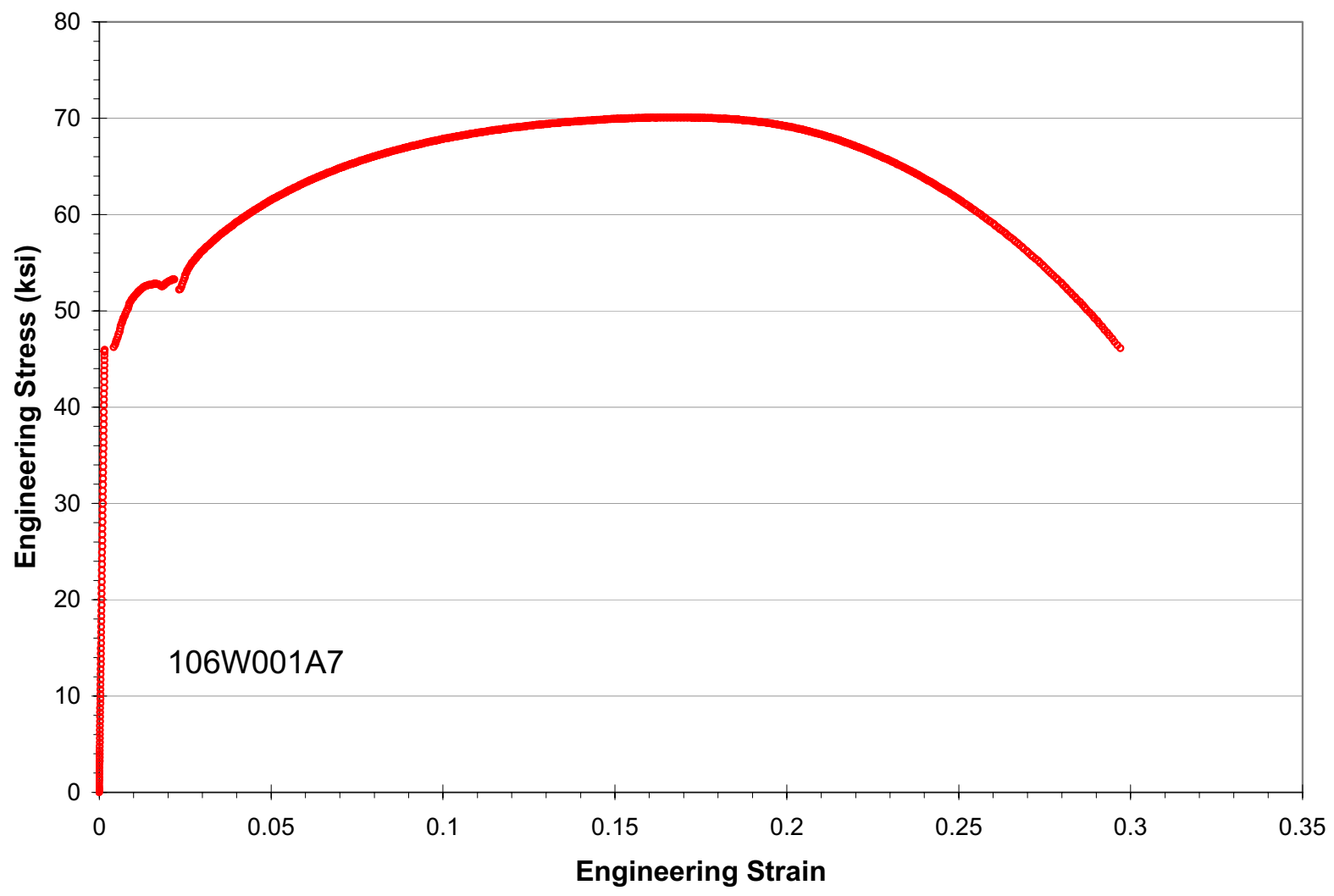

Figure 23: Engineering Stress vs. Strain for Sample \# 106W001A7 (Weld Metal in Air) 


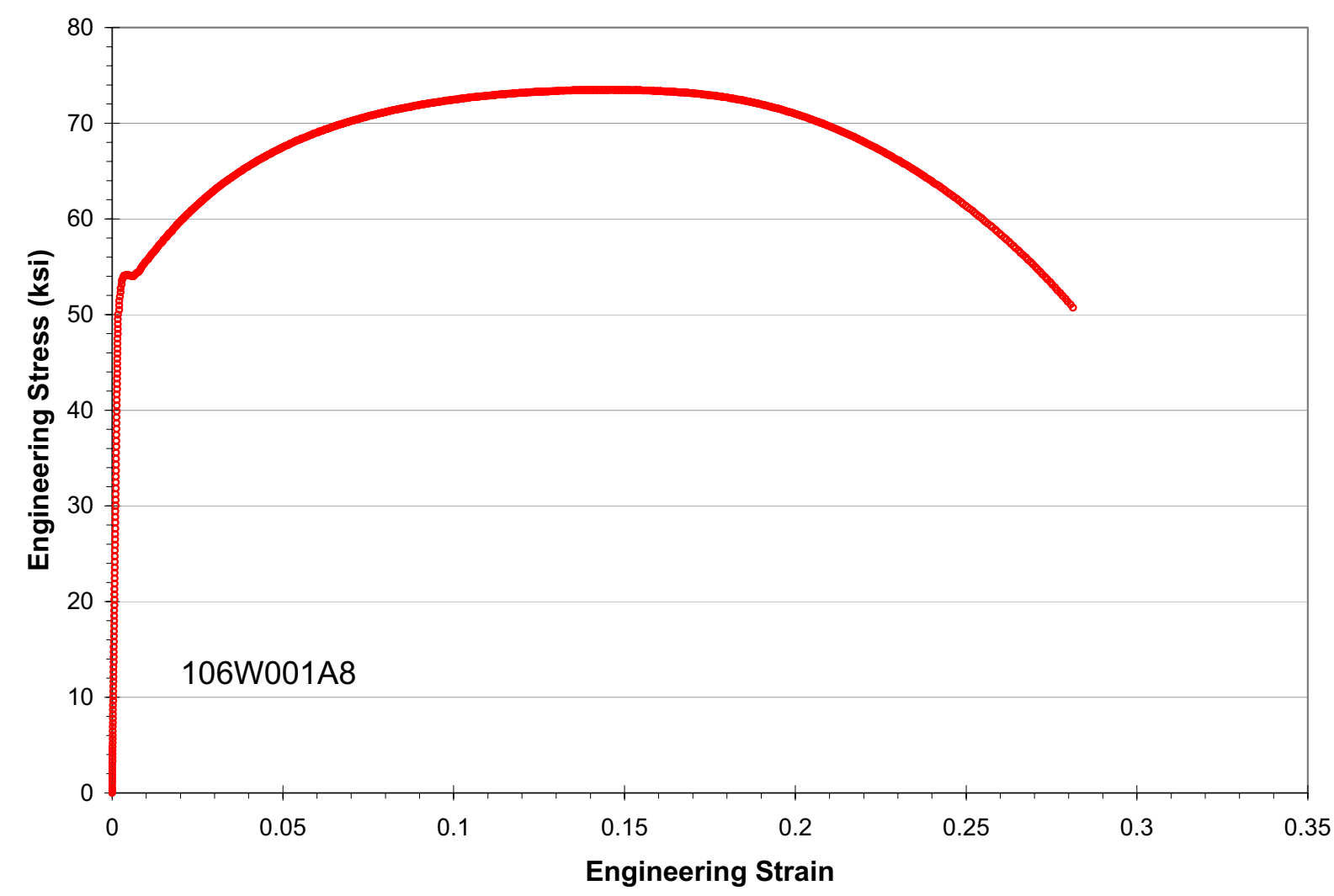

Figure 24: Engineering Stress vs. Strain for Sample \# 106W001A8 (Weld Metal in Air) 


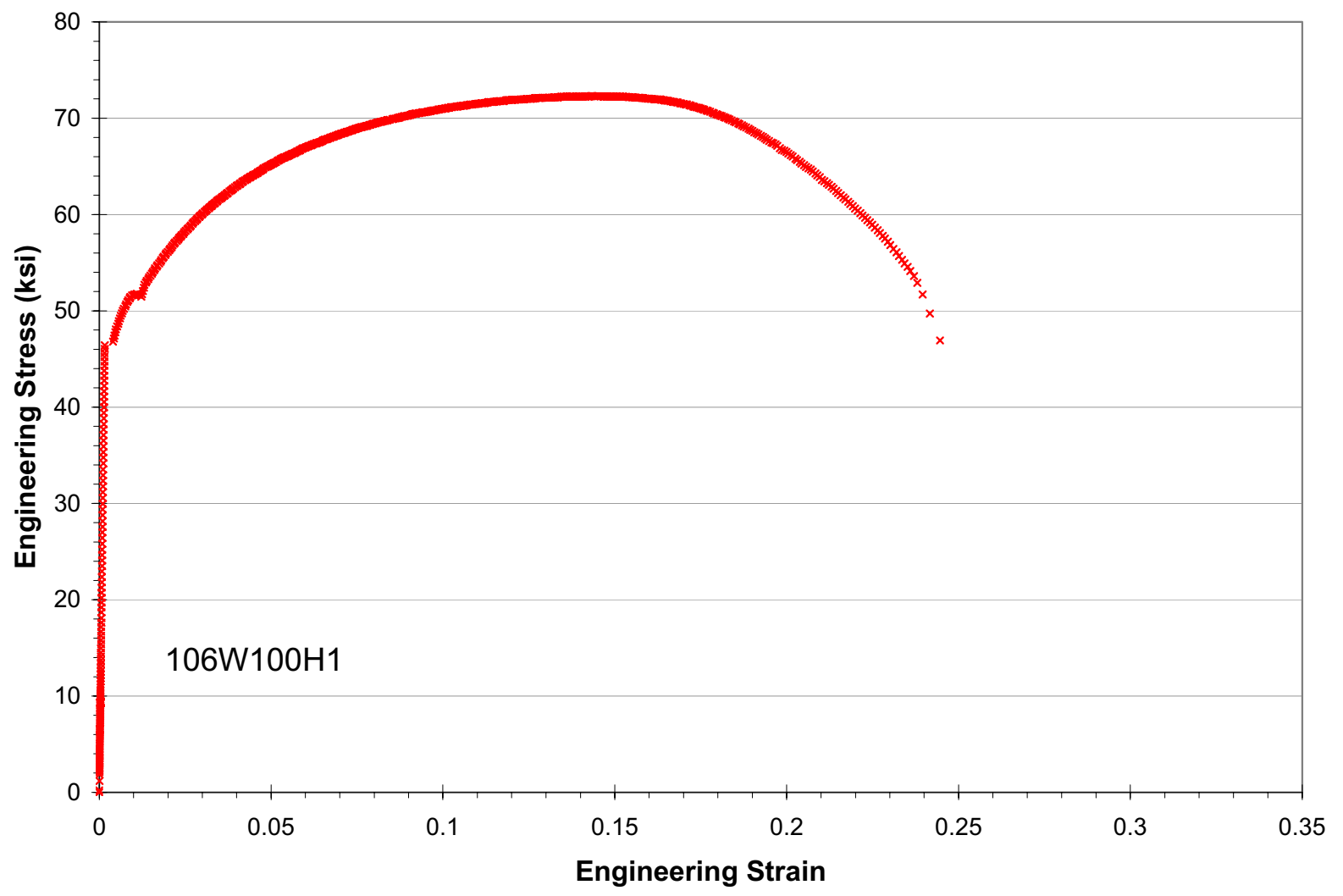

Figure 25: Engineering Stress vs. Strain for Sample \# 106W100H1 (Weld Metal in 1500 psig $\mathbf{H}_{2}$ ) 


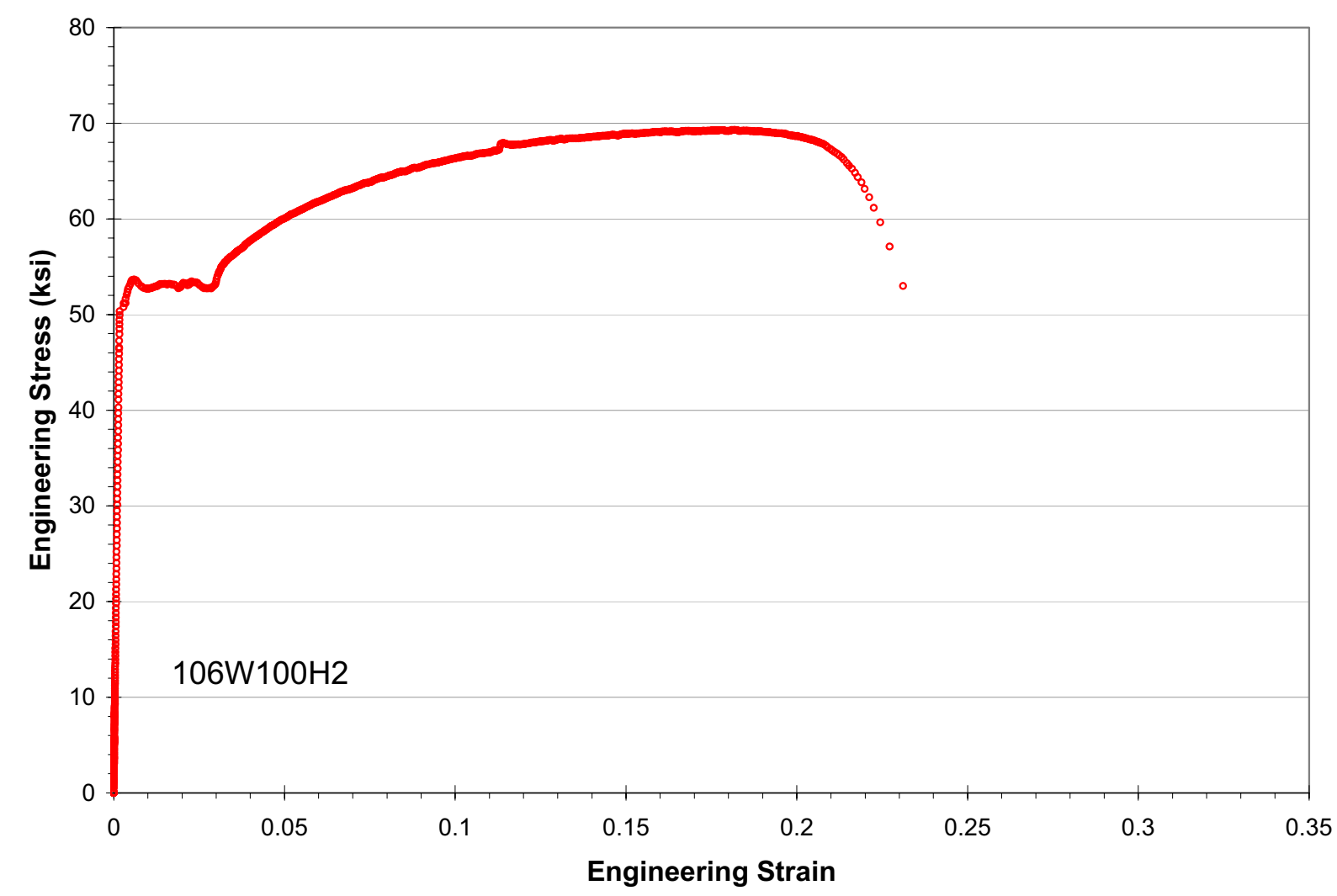

Figure 26: Engineering Stress vs. Strain for Sample \# 106W100H2 (Weld Metal in 1500 psig $\mathrm{H}_{2}$ ) 


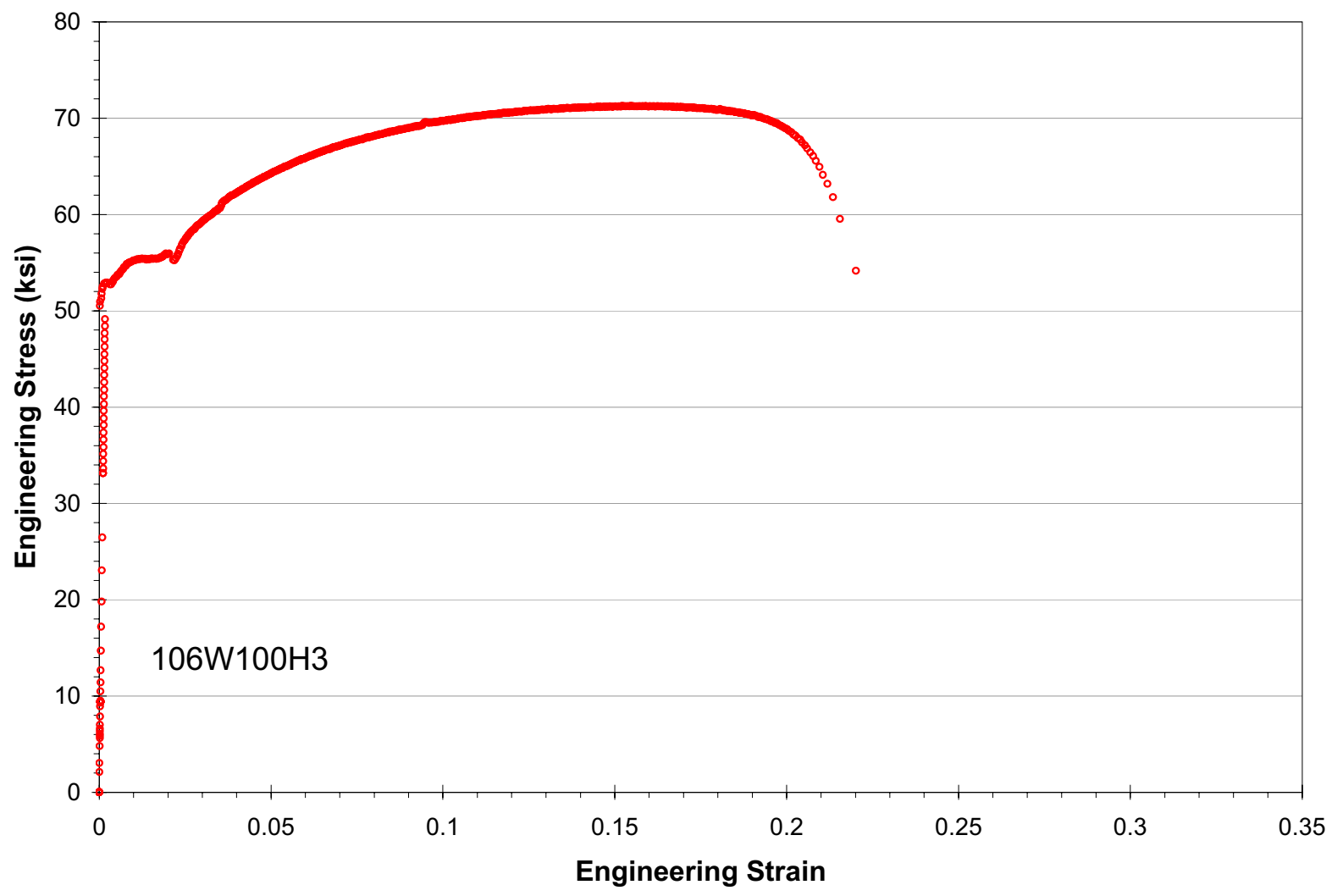

Figure 27: Engineering Stress vs. Strain for Sample \# 106W100H3 (Weld Metal in 1500 psig $\mathbf{H}_{2}$ ) 


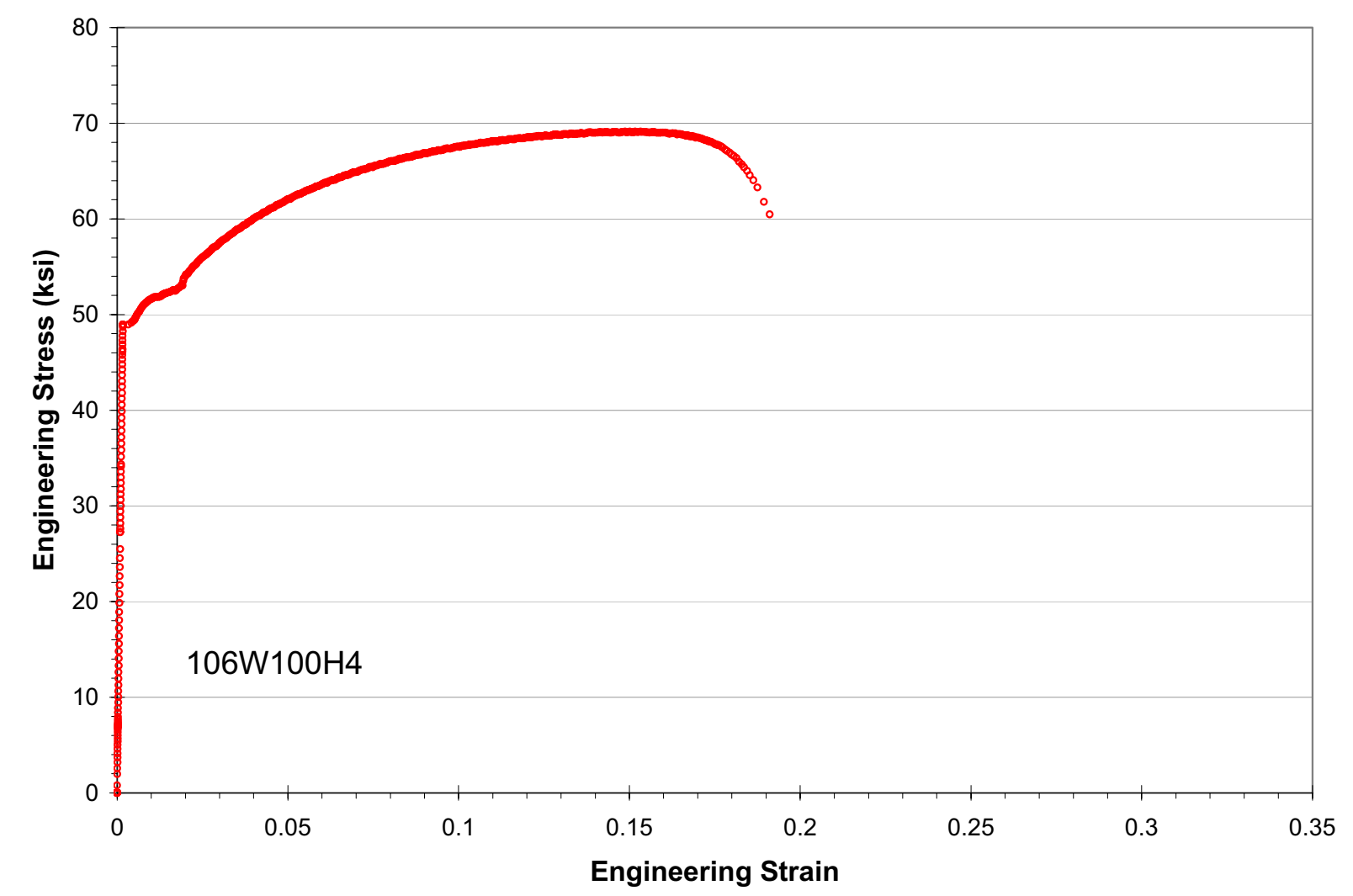

Figure 28: Engineering Stress vs. Strain for Sample \# 106W100H4 (Weld Metal in 1500 psig $\mathbf{H}_{2}$ ) 


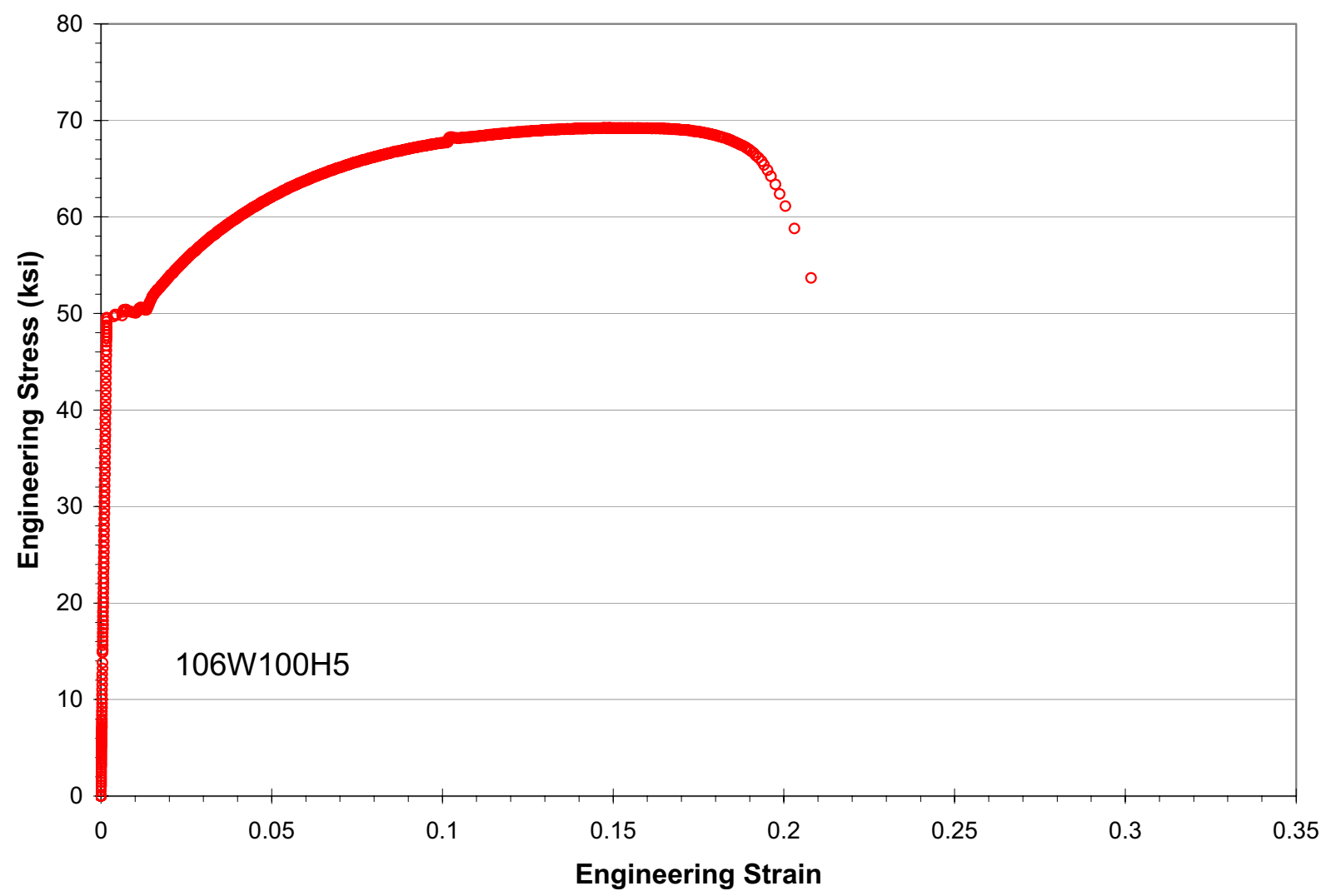

Figure 29: Engineering Stress vs. Strain for Sample \# 106W100H5 (Weld Metal in 1500 psig $\mathbf{H}_{2}$ ) 


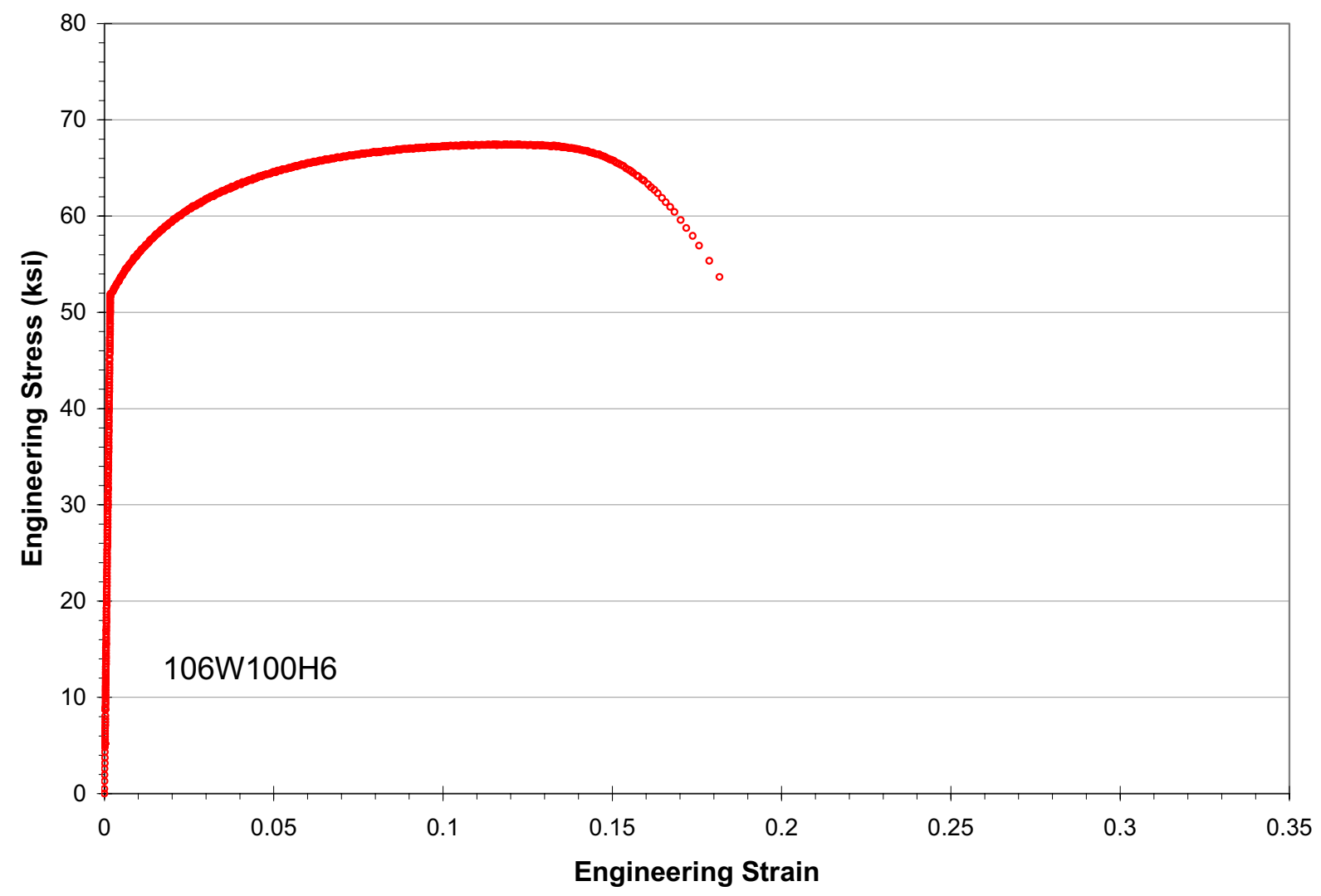

Figure 30: Engineering Stress vs. Strain for Sample \# 106W100H6 (Weld Metal in 1500 psig $\mathbf{H}_{2}$ ) 


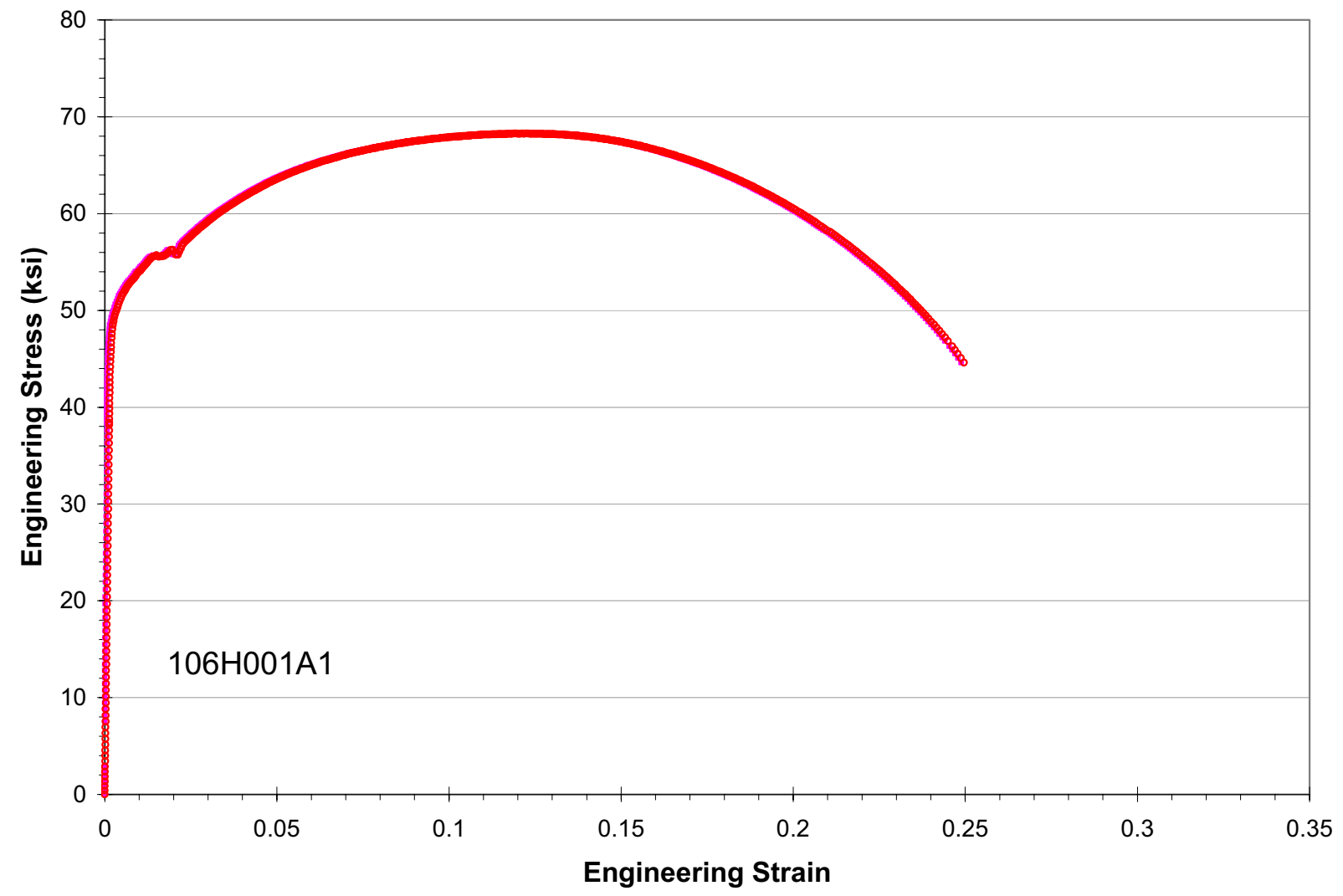

Figure 31: Engineering Stress vs. Strain for Sample \# 106H001A1 (HAZ in Air) 


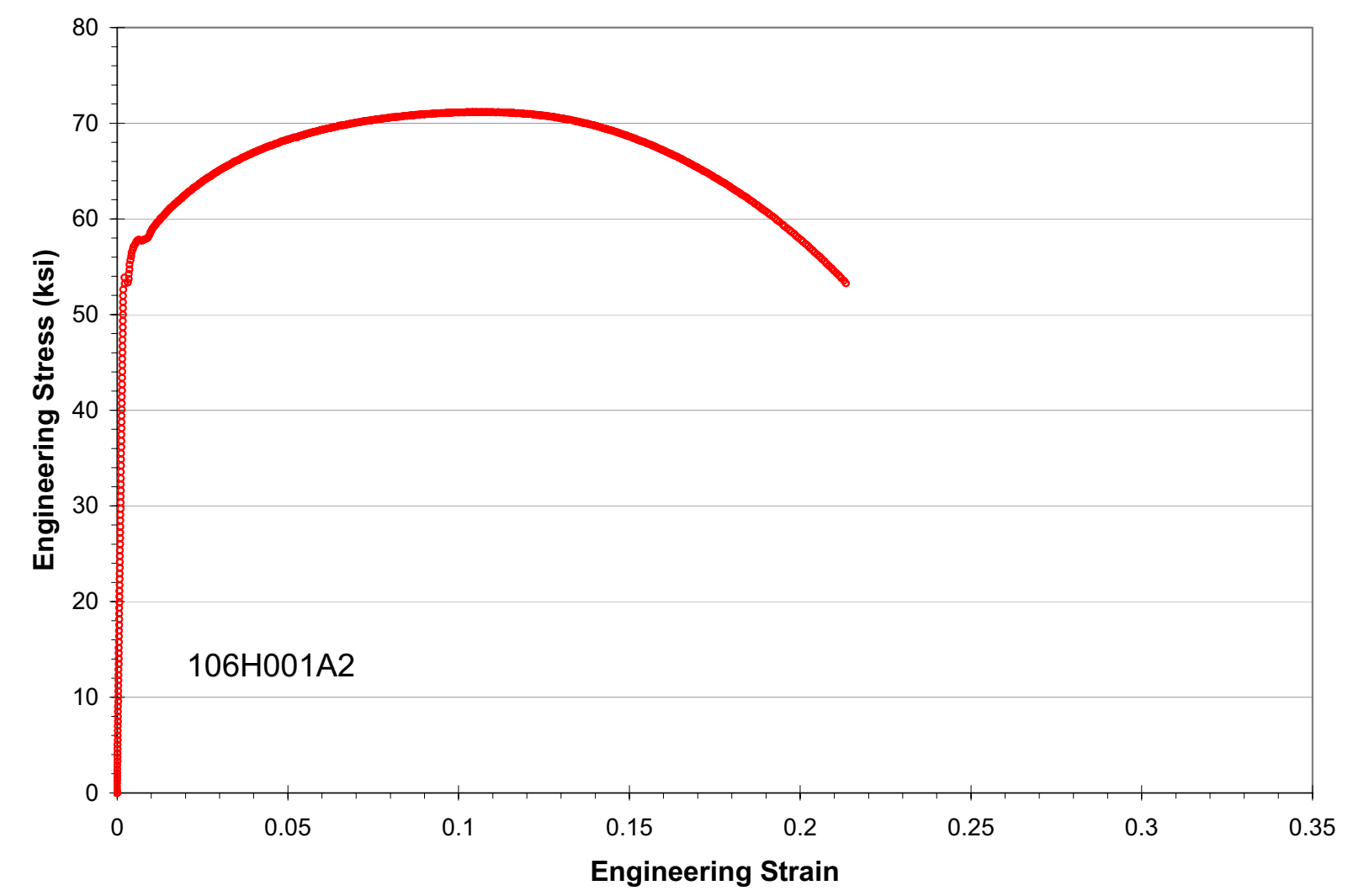

Figure 32: Engineering Stress vs. Strain for Sample \# 106H001A2 (HAZ in Air) 


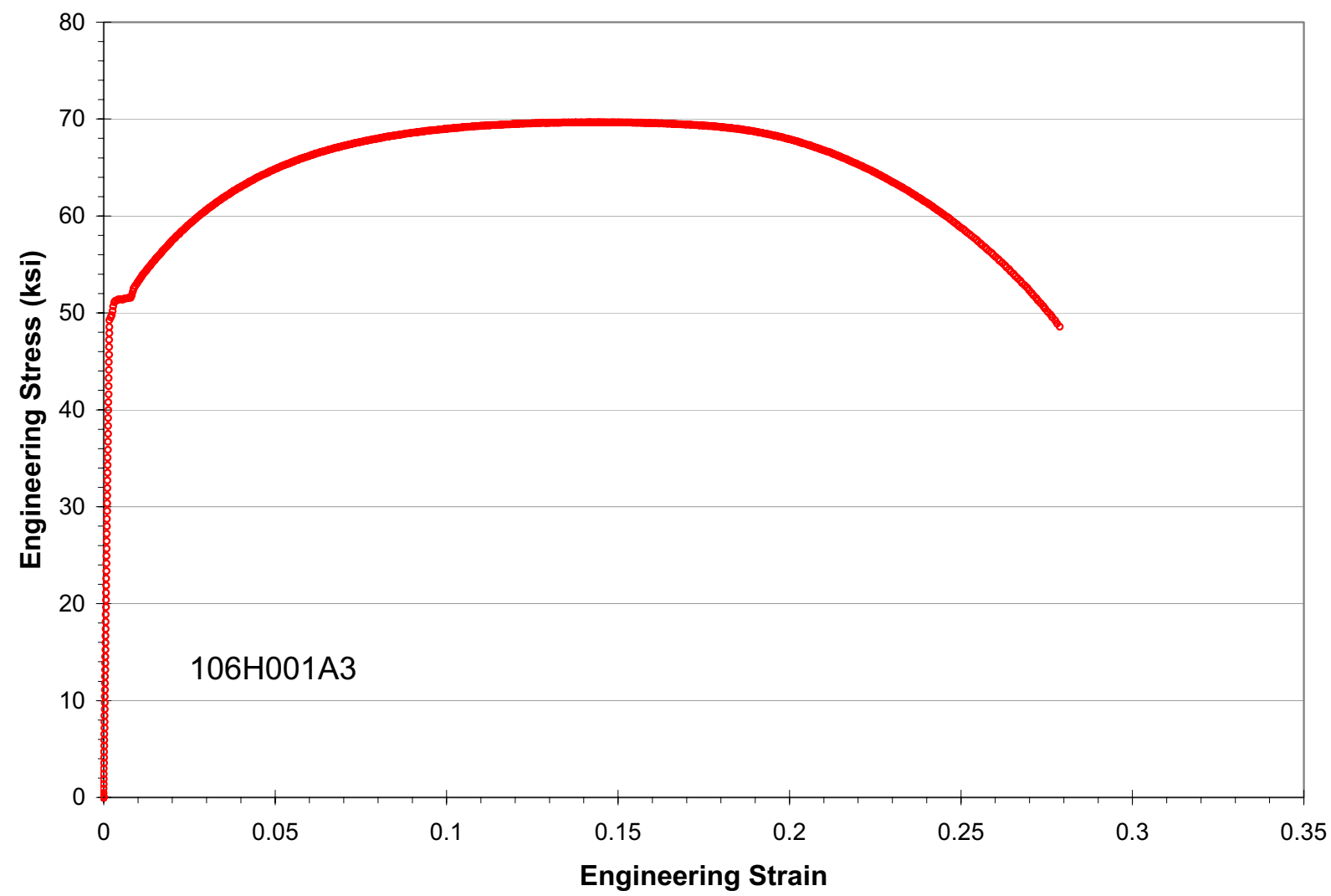

Figure 33: Engineering Stress vs. Strain for Sample \# 106H001A3 (HAZ in Air) 


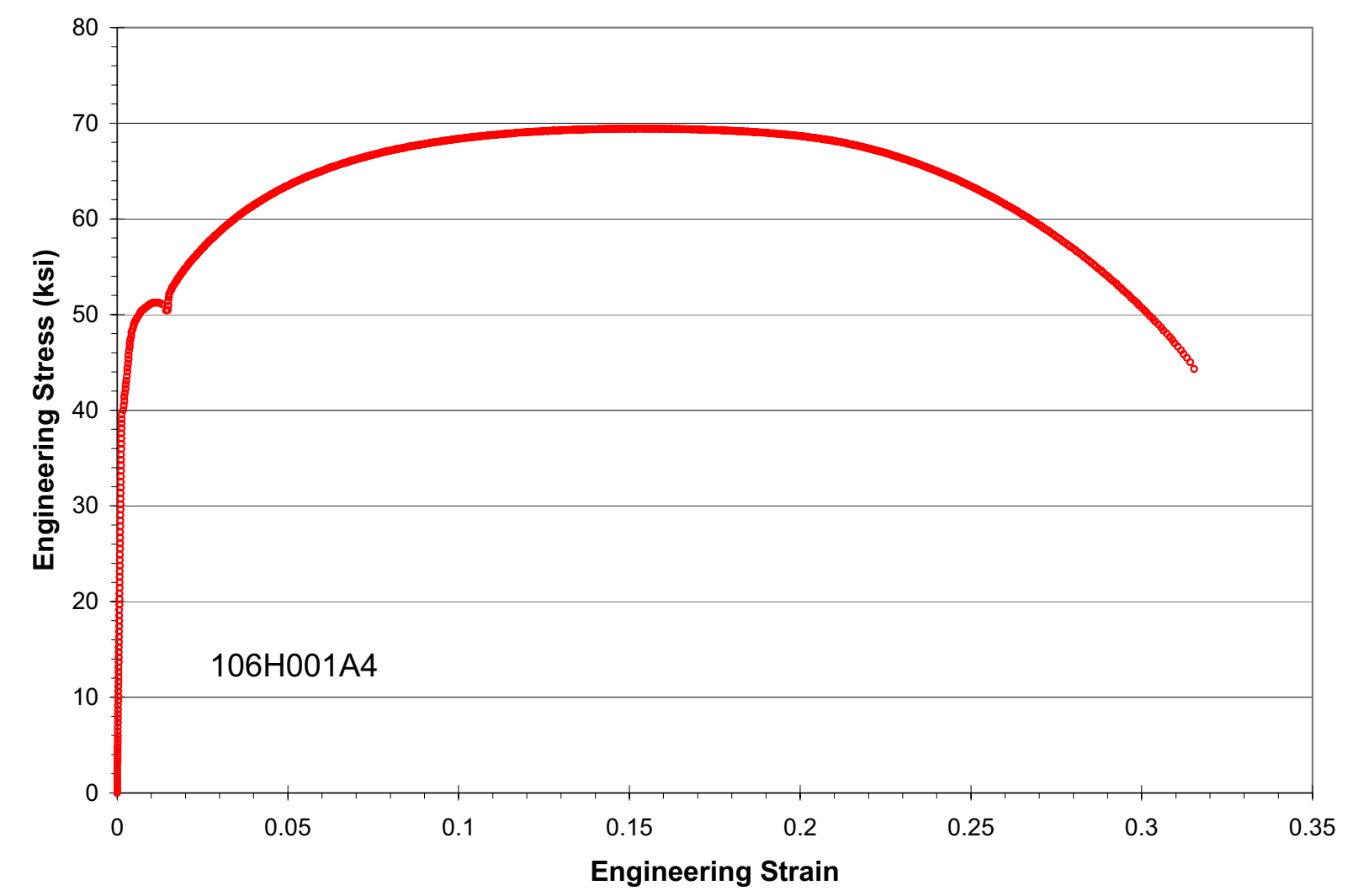

Figure 34: Engineering Stress vs. Strain for Sample \# 106H001A4 (HAZ in Air) 


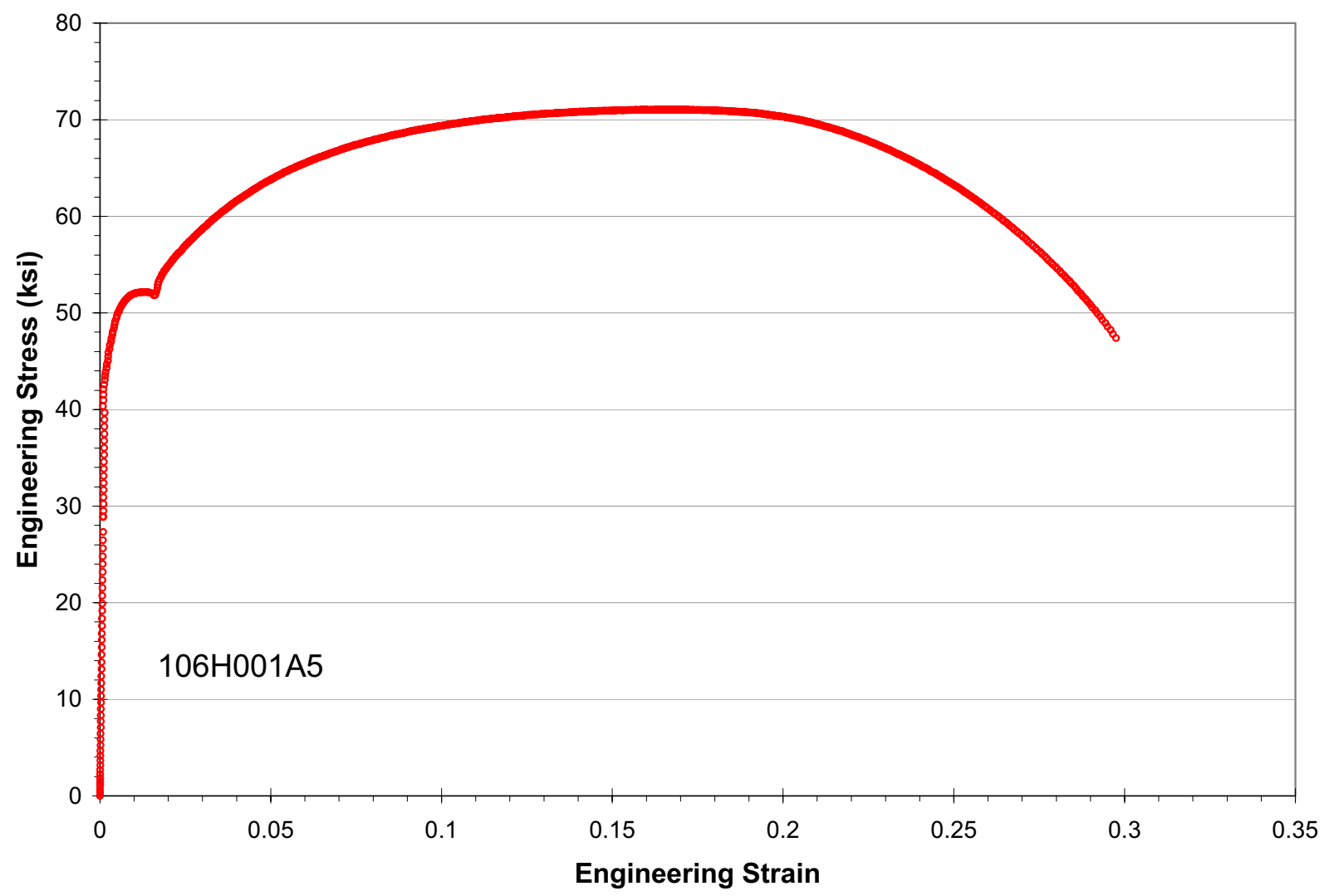

Figure 35: Engineering Stress vs. Strain for Sample \# 106H001A5 (HAZ in Air) 


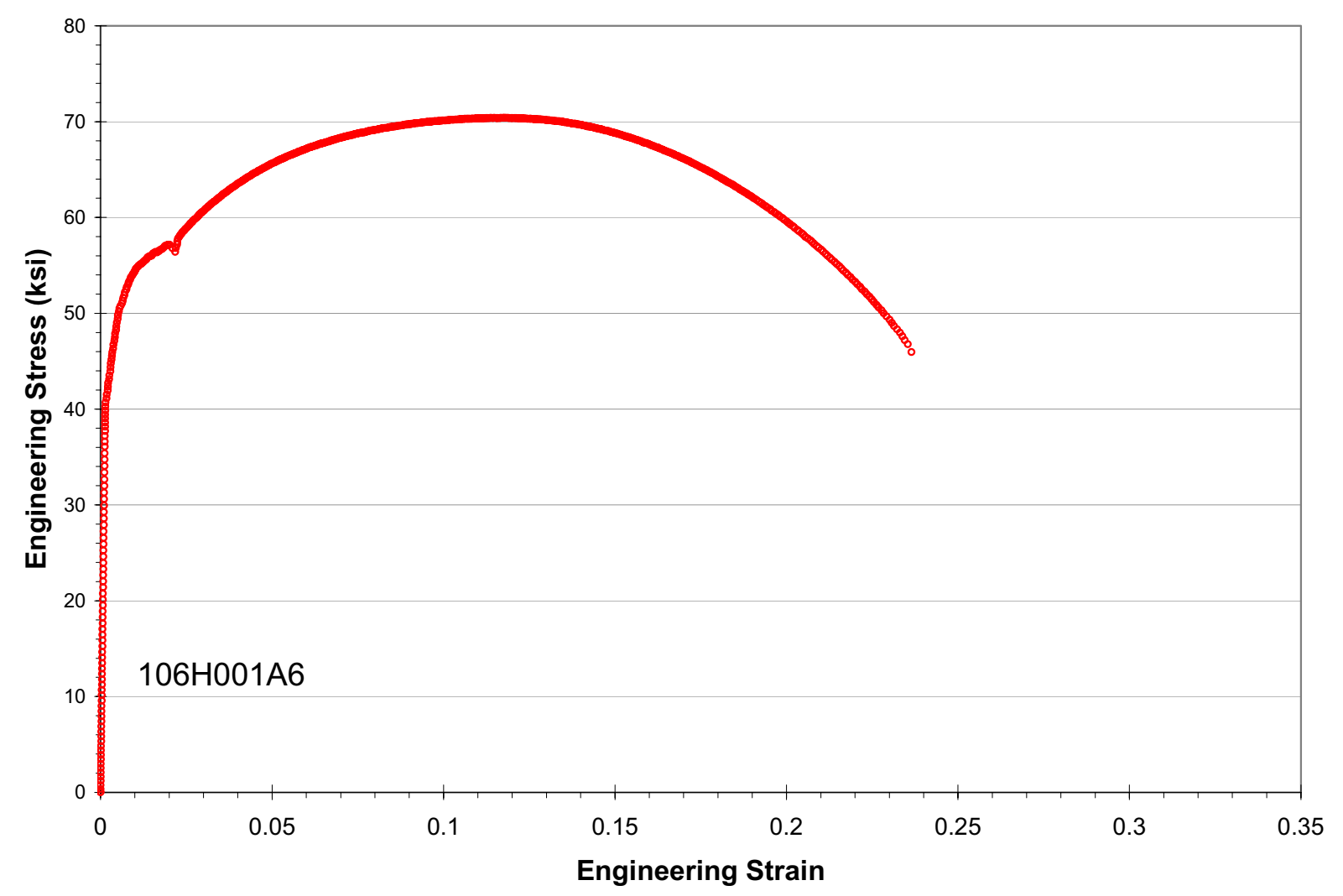

Figure 36: Engineering Stress vs. Strain for Sample \# 106H001A6 (HAZ in Air) 


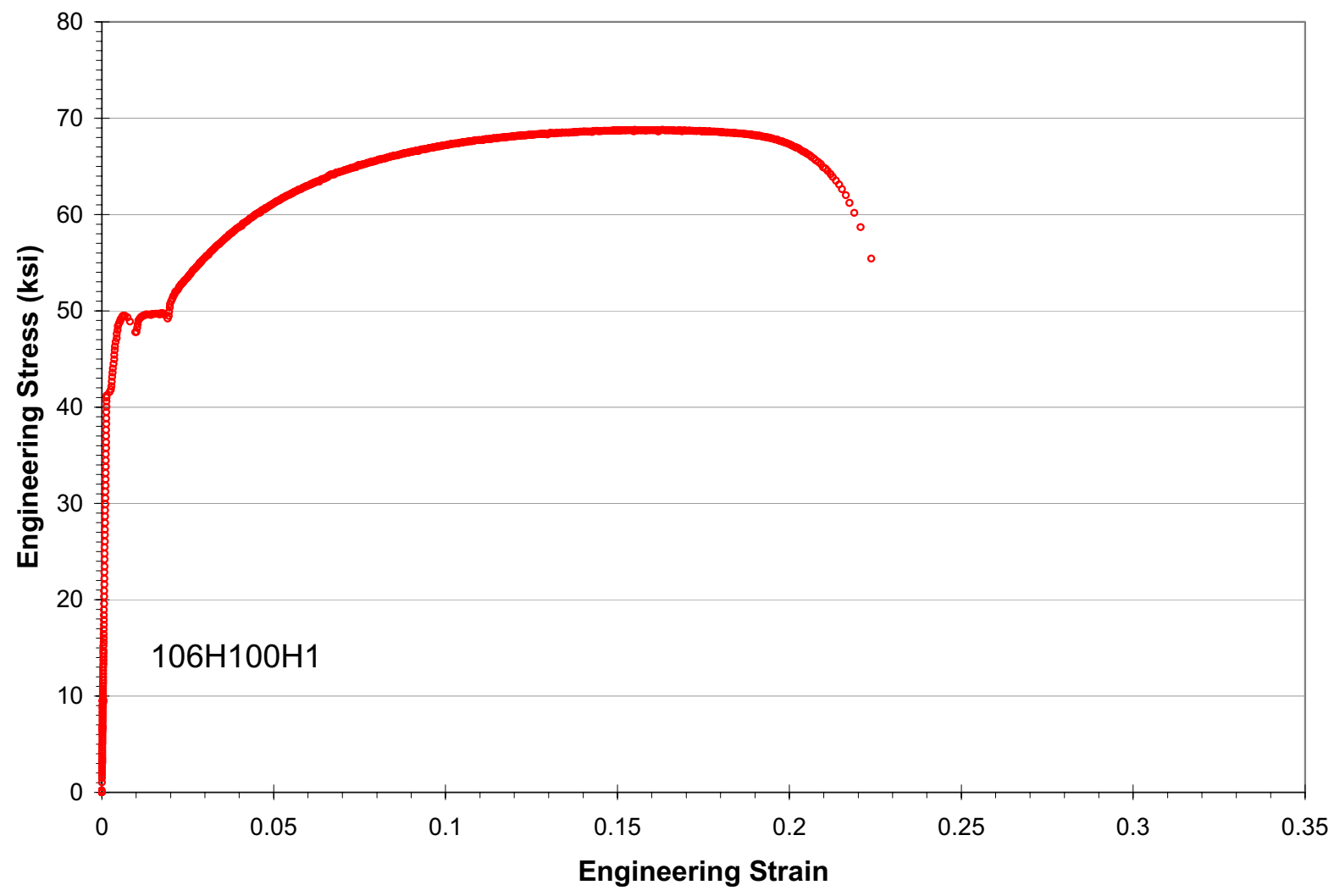

Figure 37: Engineering Stress vs. Strain for Sample \# 106H100H1 (HAZ in 1500 psig $\left.\mathrm{H}_{2}\right)$ 


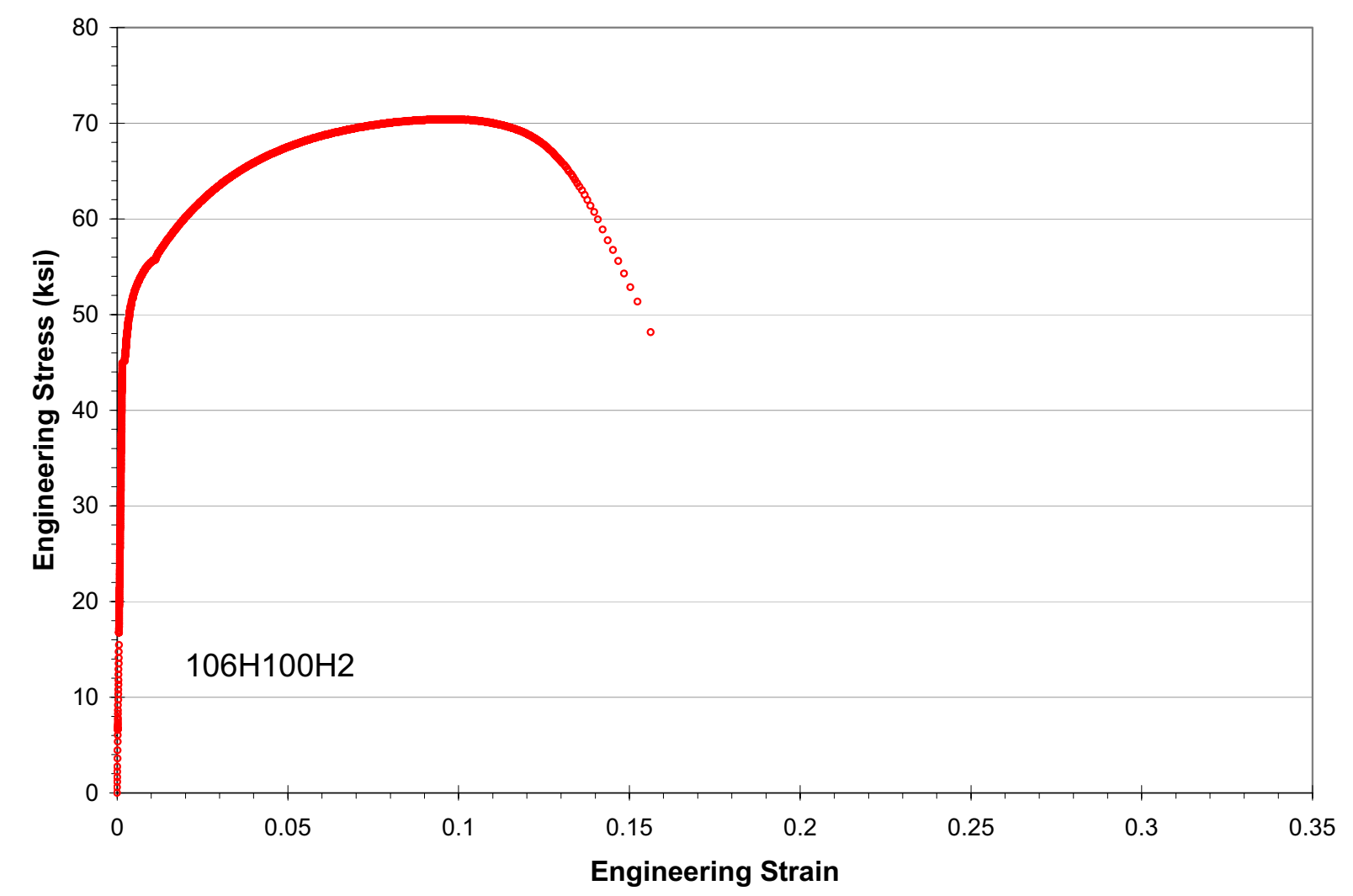

Figure 38: Engineering Stress vs. Strain for Sample \# 106H100H1 (HAZ in 1500 psig H$\left._{2}\right)$ 


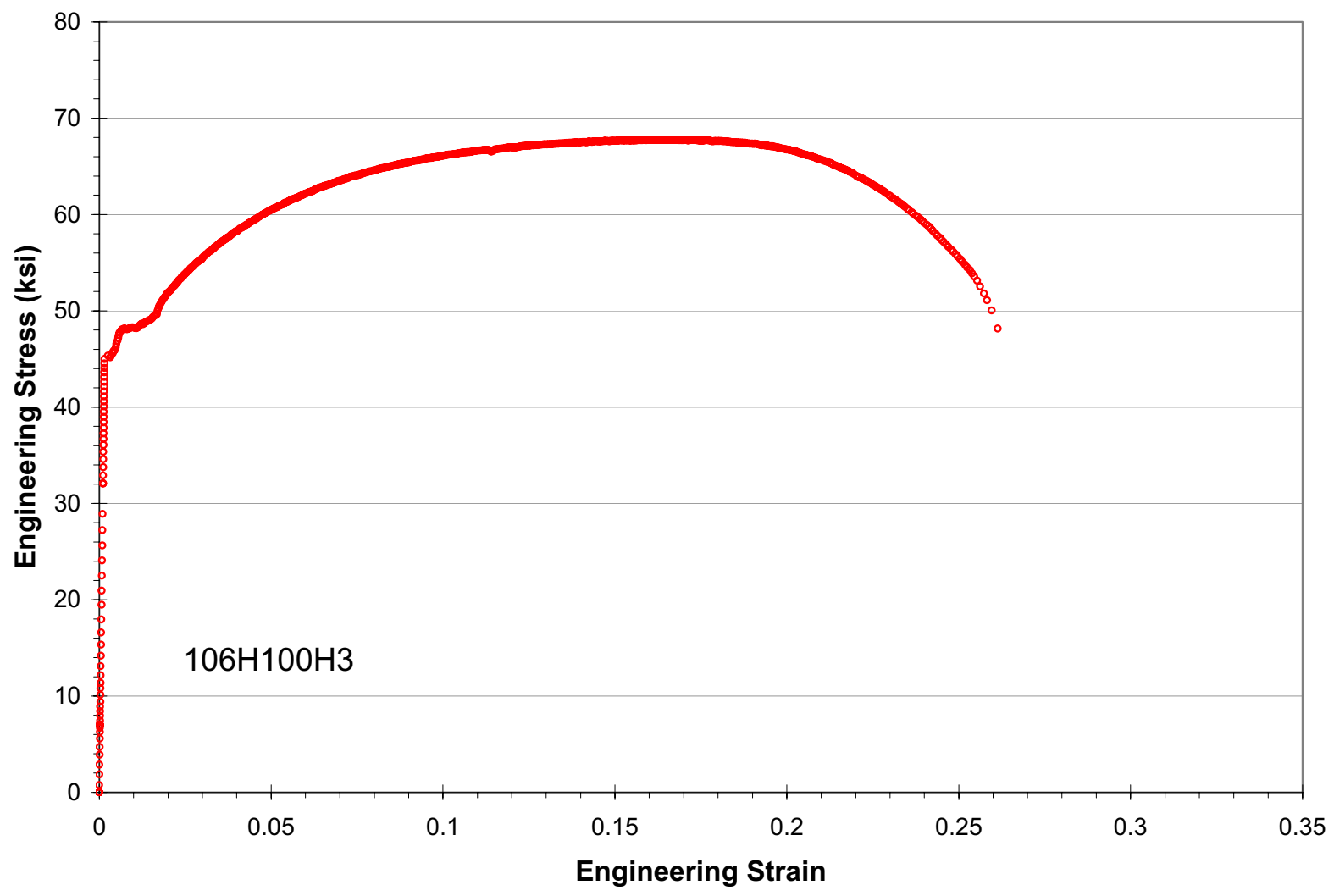

Figure 39: Engineering Stress vs. Strain for Sample \# 106H100H1 (HAZ in 1500 psig $\left.\mathrm{H}_{2}\right)$ 


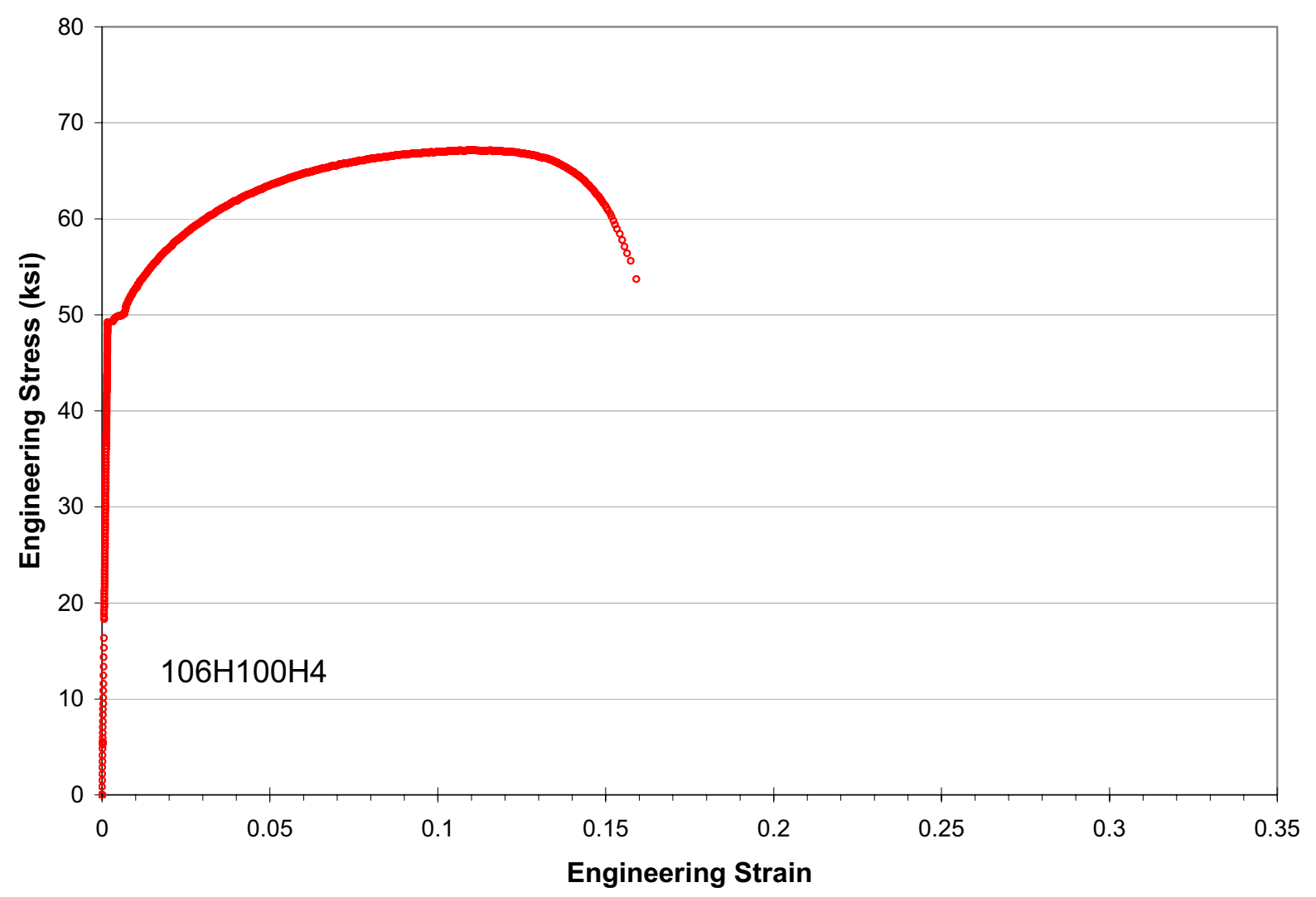

Figure 40: Engineering Stress vs. Strain for Sample \# 106H100H1 (HAZ in 1500 psig $\left.\mathrm{H}_{2}\right)$ 


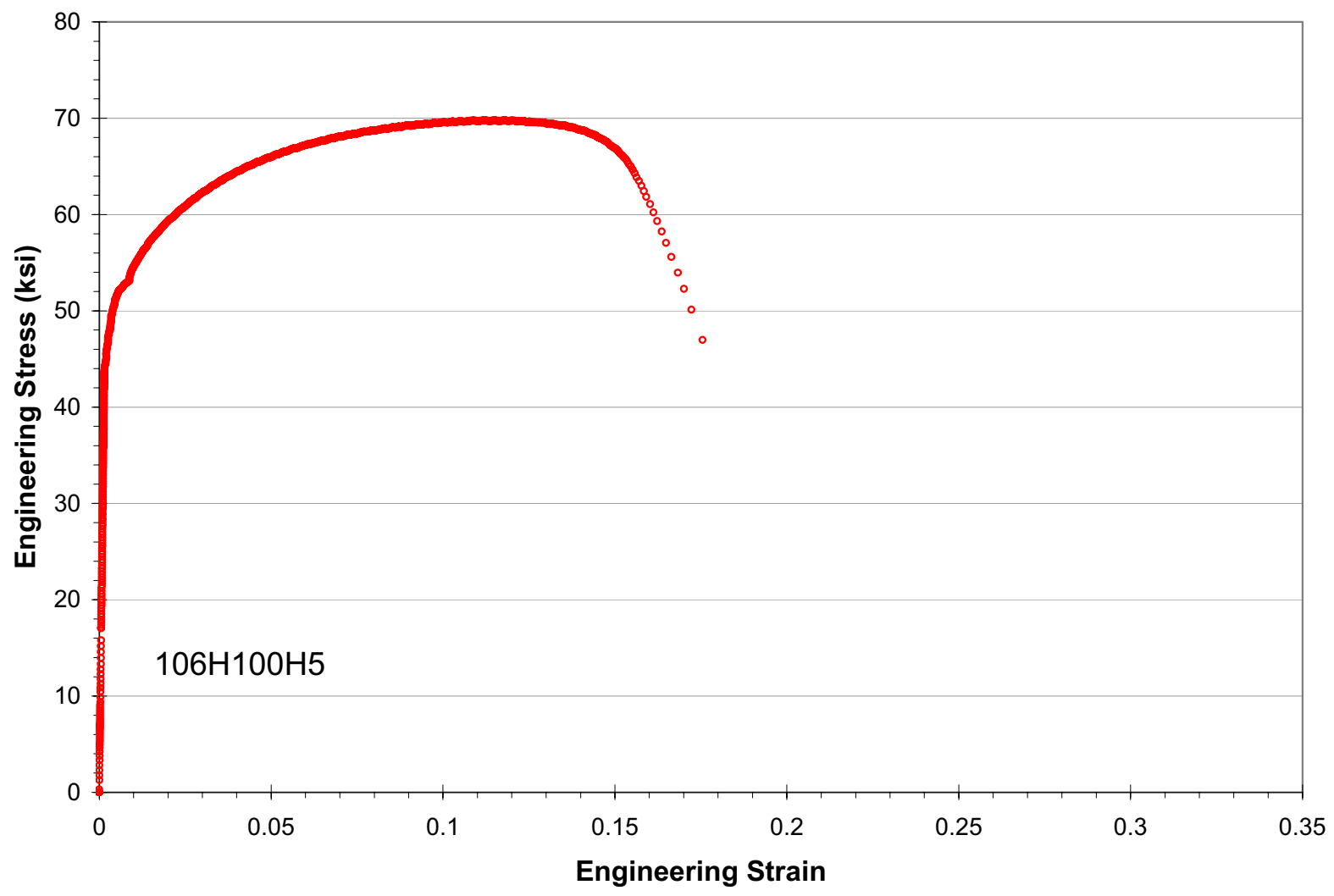

Figure 41: Engineering Stress vs. Strain for Sample \# 106H100H1 (HAZ in 1500 psig $\left.\mathrm{H}_{2}\right)$ 


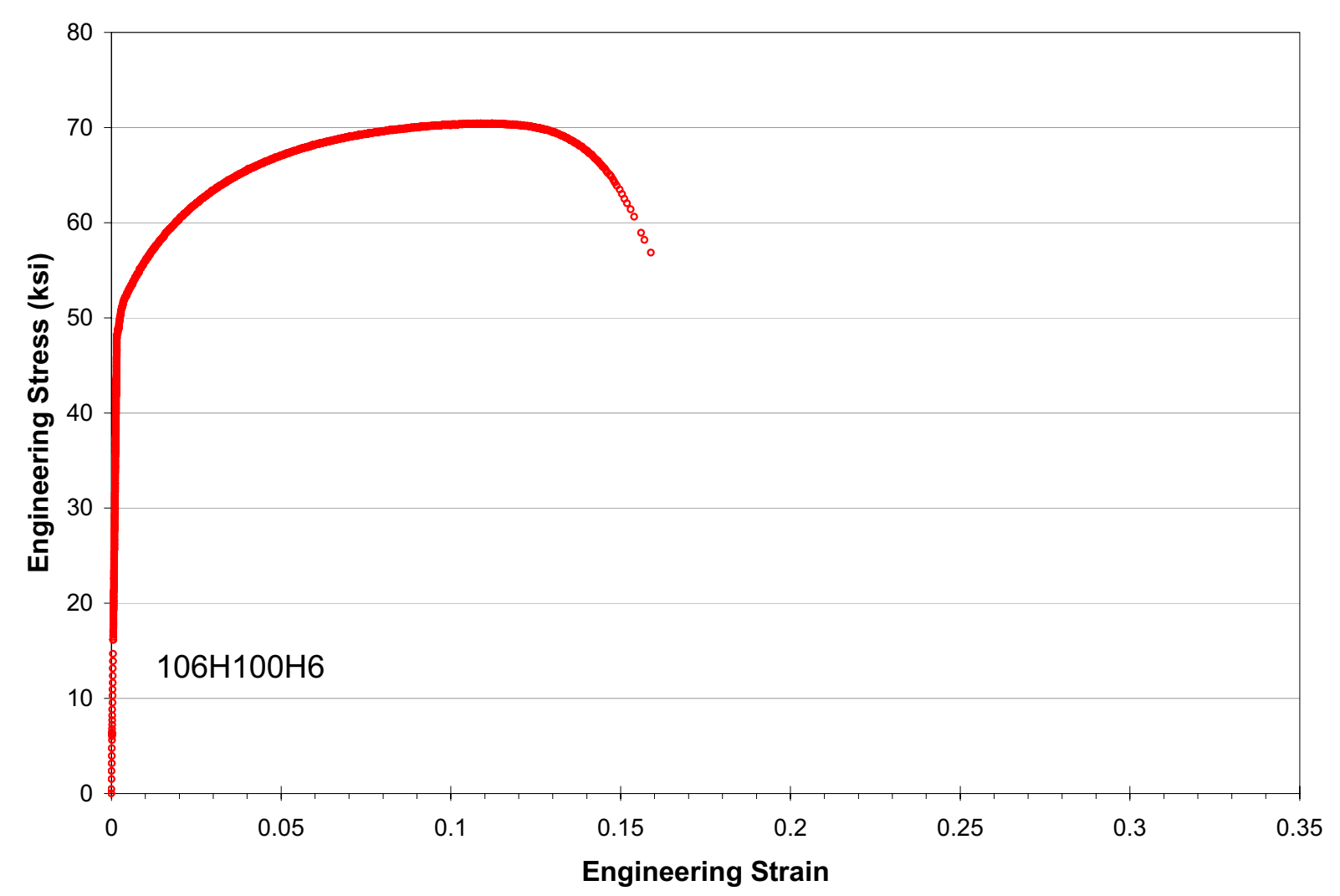

Figure 42: Engineering Stress vs. Strain for Sample \# 106H100H1 (HAZ in 1500 psig $\left.\mathrm{H}_{2}\right)$ 
Table III: Tensile Property Results

\begin{tabular}{|c|c|c|c|c|c|c|c|c|}
\hline & Sample & \multicolumn{3}{|c|}{1 ATM (Air) } & \multirow[t]{2}{*}{ Sample } & \multicolumn{3}{|c|}{100 ATM (H2) } \\
\hline & & $\begin{array}{l}\text { Yield } \\
\text { (ksi) }\end{array}$ & $\begin{array}{l}\text { UTS } \\
\text { (ksi) }\end{array}$ & $\begin{array}{l}\text { Elong. } \\
\text { at } \\
\text { failure }\end{array}$ & & $\begin{array}{l}\text { Yield } \\
\text { (ksi) }\end{array}$ & $\begin{array}{l}\text { UTS } \\
\text { (ksi) }\end{array}$ & $\begin{array}{l}\text { Elong. } \\
\text { at } \\
\text { failure }\end{array}$ \\
\hline \multirow{8}{*}{ 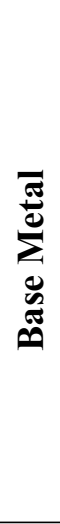 } & 106B001A1 & 52.2 & 69.7 & 0.343 & 106B100H1 & 58.1 & 72.2 & 0.159 \\
\hline & $106 \mathrm{~B} 001 \mathrm{~A} 3$ & 53.2 & 69.5 & 0.248 & 106B100H2 & 48.1 & 69.6 & 0.157 \\
\hline & 106B001A5 & 47.9 & 68.8 & 0.343 & 106B100H3 & 47.5 & 68.3 & 0.249 \\
\hline & 106B001A7 & 51.8 & 71.7 & 0.238 & 106B100H4 & 56.6 & 71.1 & 0.170 \\
\hline & 106B001A8 & 54.2 & 71.9 & 0.296 & 106B100H5 & 52.9 & 74.5 & 0.174 \\
\hline & 106B001A9 & 49.9 & 70.1 & 0.300 & 106B100H6 & 47.6 & 67.6 & 0.225 \\
\hline & AVERAGE & 51.5 & 70.3 & 0.29 & & 51.8 & 70.6 & 0.19 \\
\hline & STDEV & 2.3 & 1.3 & 0.04 & & 4.8 & 2.6 & 0.04 \\
\hline \multirow{8}{*}{$\begin{array}{l}\frac{\pi}{0} \\
\frac{\pi}{0} \\
\frac{0}{0} \\
3\end{array}$} & 106W001A1 & 50.7 & 70.5 & 0.288 & 106W100H1 & 47.4 & 72.3 & 0.245 \\
\hline & 106W001A2 & 46.5 & 70.1 & 0.261 & 106W100H2 & 52.1 & 69.3 & 0.231 \\
\hline & 106W001A4 & 50.8 & 71.3 & 0.283 & $106 \mathrm{~W} 100 \mathrm{H} 3$ & 53.2 & 71.2 & 0.220 \\
\hline & 106W001A6 & 49.9 & 71.4 & 0.292 & $106 \mathrm{~W} 100 \mathrm{H} 4$ & 49.1 & 69.1 & 0.191 \\
\hline & 106W001A7 & 46.5 & 70 & 0.297 & 106W100H5 & 49.9 & 69.2 & 0.207 \\
\hline & 106W001A8 & 54.1 & 73.5 & 0.281 & 106W100H6 & 52.9 & 67.4 & 0.182 \\
\hline & AVERAGE & 49.8 & 71.1 & 0.28 & & 50.8 & 69.8 & 0.21 \\
\hline & STDEV & 2.9 & 1.3 & 0.01 & & 2.3 & 1.7 & 0.02 \\
\hline \multirow{8}{*}{$\geqq$} & $106 \mathrm{H} 001 \mathrm{~A} 1$ & 51.2 & 68.2 & 0.25 & 106H100H1 & 45.9 & 68.7 & 0.224 \\
\hline & $106 \mathrm{H} 001 \mathrm{~A} 2$ & 56.1 & 71.1 & 0.213 & $106 \mathrm{H} 100 \mathrm{H} 2$ & 51.1 & 70.4 & 0.156 \\
\hline & $106 \mathrm{H} 001 \mathrm{~A} 3$ & 51.4 & 69.6 & 0.279 & $106 \mathrm{H} 100 \mathrm{H} 3$ & 45.6 & 67.6 & 0.261 \\
\hline & $106 \mathrm{H} 001 \mathrm{~A} 4$ & 48.2 & 69.4 & 0.315 & $106 \mathrm{H} 100 \mathrm{H} 4$ & 49.7 & 67.1 & 0.159 \\
\hline & 106H001A5 & 48.5 & 71.0 & 0.297 & 106H100H5 & 50.0 & 69.7 & 0.176 \\
\hline & $106 \mathrm{H} 001 \mathrm{~A} 6$ & 48.6 & 70.4 & 0.236 & 106H100H6 & 52.0 & 70.3 & 0.159 \\
\hline & AVERAGE & 50.7 & 70.0 & 0.27 & & 49.1 & 69.0 & 0.19 \\
\hline & STDEV & 3.0 & 1.1 & 0.04 & & 2.7 & 1.4 & 0.04 \\
\hline
\end{tabular}




\subsection{SUMMARY AND CONCLUSIONS}

This study reports the interim results from the testing program to support the evaluation of the use of new and existing pipelines and systems to carry and to deliver hydrogen as an alternative energy source under the hydrogen economy. The carbon steels alloy A106 Grade B was selected because of its common application in pipelines. The results of a matrix of tensile tests performed at room temperature in air and in high pressure hydrogen were reported.

A general reduction of the ductility or deformation capacity was noted in this material. The elongation to failure and reduction in area was reduced when specimens were tested in 1500 psig hydrogen.

Furthermore, the primary mode of fracture changed from ductile rupture to cleavage.

Tests to quantify the fracture behavior in terms of J-R curves for these materials at air and hydrogen pressure conditions are being planned.

\subsection{ACKNOWLEDGEMENTS}

The technical input of Thad Adams, Glenn Chapman, Mike Morgan and Joel Jones toward the development of the experimental approach is gratefully acknowledged. Technical review of this manuscript was performed by Thad Adams.

\subsection{REFERENCES}

${ }^{1}$ ASTM Designation \#A106-06, Standard Specification for Seamless Carbon Steel Pipe for High-Temperature Service, American Society for Testing Materials, West Conshohoken, PA (2006)

${ }^{2}$ Specification for Line Pipe, API Specification 5L, 43 ${ }^{\text {rd }}$ edition, October 2004, American Petroleum Institute, Houston TX (2004)

${ }^{3}$ WPS \# P1-TA, Rev. 2 SRS Welding Procedure Specification for Welding Carbon Steel Using the GTAW and SMAW Processes, SRS, Aiken, SC, 9/26/03.

${ }^{4}$ Lam, P.S., Morgan M. J., Imrich K. J. and Chapman, G. K., "Predicting Tritium and Decay Helium Effects on Burst Properties of Pressure Vessels," Proceedings of PVP2006-ICPVT-11: 2006 ASME Pressure Vessels and Piping Conference July 23-27, 2006, Vancouver, BC, Canada

${ }^{5}$ Lam, P.-S., Technical Report \# WSRC-TR-2006-00119 Rev. 0, "Gaseous Hydrogen Effects on the Mechanical Properties of Carbon and Low Alloy Steels (U)," WSRC, Aiken, SC 29808, (2006) 
WSRC-TR-2006-00180, Rev. 0

\section{Distribution}

\section{$\underline{\text { Savannah River Site }}$}

N. C. Iyer, 773-41A

R. L. Sindelar, 773-41A

T. M. Adams, 773-41A

A. J. Duncan, 773-A

G. B. Rawls, 773-41A

E. A. Clark, 773-A

E. W. Hotlzscheiter, Jr., 773-A

T. Motyka, 773-A

P. S. Lam, 773-41A

\section{$\underline{\text { External }}$}

L. J. Eslin, Concurrent Technologies Corporation

F. R. Dax, Concurrent Technologies Corporation 